Portland State University

PDXScholar

6-21-1994

\title{
A Linguistic Needs Assessment of a Latino Community
}

Cybele Marie Higgins

Portland State University

Follow this and additional works at: https://pdxscholar.library.pdx.edu/open_access_etds

Part of the Bilingual, Multilingual, and Multicultural Education Commons Let us know how access to this document benefits you.

\section{Recommended Citation}

Higgins, Cybele Marie, "A Linguistic Needs Assessment of a Latino Community" (1994). Dissertations and Theses. Paper 4819.

https://doi.org/10.15760/etd.6695

This Thesis is brought to you for free and open access. It has been accepted for inclusion in Dissertations and Theses by an authorized administrator of PDXScholar. Please contact us if we can make this document more accessible: pdxscholar@pdx.edu. 
THESIS APPROVAL

The abstract and thesis of Cybele Marie Higgins for the Master of Arts in Teaching English to Speakers of Other Languages were presented June 21, 1994, and accepted by the thesis committee and the department.

COMMITTEE APPROVALS:

$$
\text { Marjorie Terdal, Chair }
$$

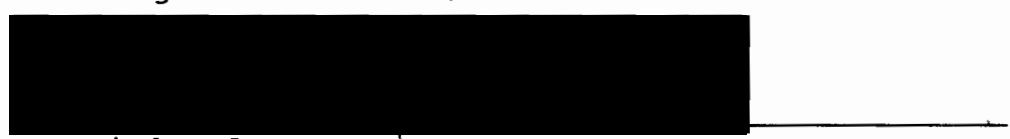

Kimbepley Brown

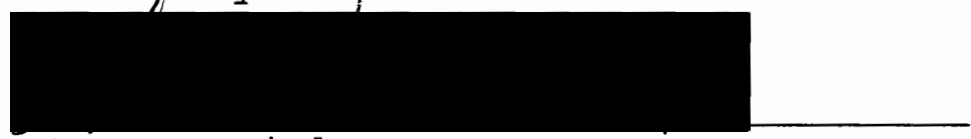

Susan Danielson

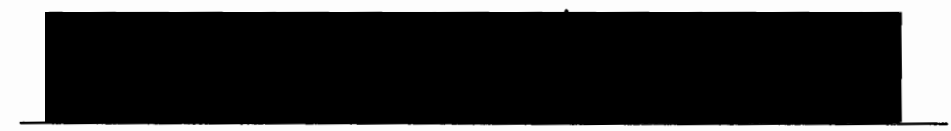

Maria Wilson-Figueroa

Representative of the Office of Graduate studies

DEPARTMENT APPROVAL:

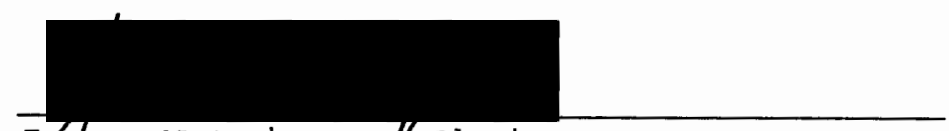

Japhes Nattinger $/$ Chair

Popartment of Applied Linguistics

ACCEPTED FOR PORTLAND STATE UNIVERSITY BY THE LIBRARY by ond 9 Soternet 1994 


\section{ABSTRACT}

An abstract of the thesis of Cybele Marie Higgins for the Master of Arts in Teaching English to Speakers of Other Languages presented June 21, 1994.

Title: A Linguistic Needs Assessment of a Latino Community .

Latino communities frequently face barriers in the midst of largely English speaking and mostly Anglo-American culture surrounding communities. These surrounding communities often may be somewhat resistant to adjusting to their changing populations.

This case study is a linguistic needs assessment of a Latino community in a small city and neighboring town in the Northwest. Discussed are experiences, needs, and opinions of thirty Latina mother participants in regards to living in this community. Participants, all of whom were monolingual Spanish or limited English proficiency recent immigrants, were recruited through a social service agency serving lowincome Latinos.

The study used observation, ethnographic-style notetaking, theme identification, and questionnaire development based on these themes, with short interviews. Seven themes 
were identified as central to participants' lives: general language issues, employment, housing, utility companies and social service agencies, medical care, child care and schools, and domestic violence.

Implications are that more affordable housing, child care, and higher paying jobs would ameliorate the lives of these low-income Latino families. Also, more bilingual and culturally competent people are needed as property managers, employers, teachers, social service workers, and especially doctors, nurses, and medical receptionists for Latino families to have equal access and for the surrounding community to integrate with its changing population.

Recommendations for English as a second language programs include development of curriculum relevant to Latina mothers' lives and teaching of linguistic strategies for living in the surrounding community. Concluding is a recommendation that studies with similar research questions be carried out in the surrounding community and in other Latino communities so, in comparing results, broader statements can be made about this population. 
A LINGUISTIC NEEDS ASSESSMENT

OF A LATINO COMMUNITY

by

CYBELE MARIE HIGGINS

A thesis submitted in partial fulfillment of the requirements for the degree of

MASTER OF ARTS

in

TEACHING ENGLISH

TO SPEAKERS OF OTHER LANGUAGES

Portland State University

1994 
Dedico éste estudio

a todas las mujeres maravillosas

que participaron

Y

a mi Cesarito 


\section{ACKNOWLEDGEMENTS}

I wish to thank Professors Marjorie Terdal and Kimberley Brown for their patience and advising in seeing this project through to its completion; Kay Cosby and Howard Ingber for their nutritional support and ears; Richard Higgins and Margaret Graff for their long-distance consulting; Chris Higgins for his wise words; and most of all, my husband césar Gutiérrez for his dedication in cheering, cooking, editing, and finding countless other ways to show his unwavering support . 
TABLE OF CONTENTS

PAGE

ACKNOWLEDGEMENTS ...............................

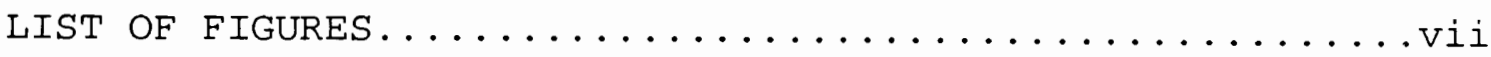

CHAPTER

I INTRODUCTION $\ldots \ldots \ldots \ldots \ldots \ldots \ldots \ldots \ldots \ldots \ldots \ldots \ldots \ldots \ldots \ldots \ldots$

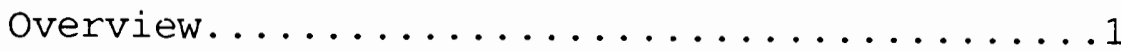

Formulation of Research Problem

Theoretical Framework

Approach

Needs Assessment

Objectives

Methods

Research Questions

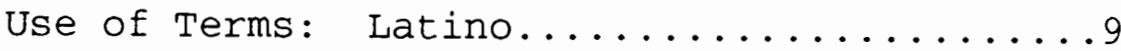

II REVIEW OF THE LITERATURE............... 13

Latinos in the United States.............14

Latino Immigrant Experiences

Acculturation and its Effects on

Psychological Distress and

Emotional Adjustment

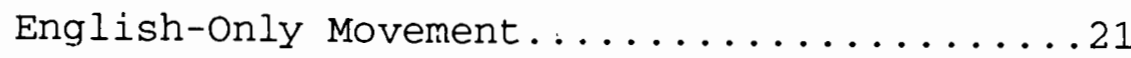

History and Objectives

Arguments for English only

Historical Precedence

Arguments Against the ELA

Possible Effects of the ELA 
Equality of Representation in Society......28

Assimilation

Ethnic Division versus Ethnic Diversity: Language as a Resource

Hidden Curriculum

Pluralistic Integration

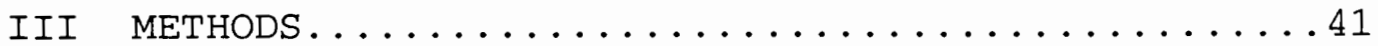

Project Location and Design...........41

The Agency

observation

Themes

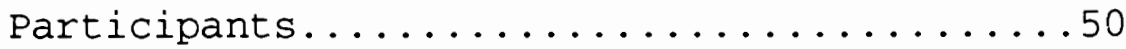

Identification

Recruitment

Description

Questionnaire and Interviews..........55

Questionnaire Format

Questionnaire/Interview Sessions

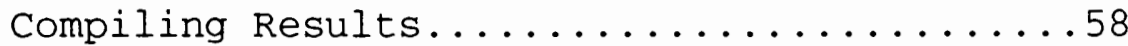

Questionnaire

Interviews

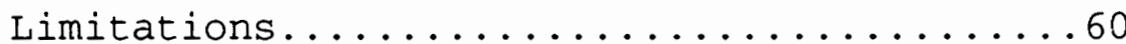

Questionnaire and Recommended Changes

Interviews and Participants' Lives

Participart Sample

IV QUANTITATIVE RESULTS: QUESTIONNAIRE.........65

Questionnaire Entries................65

Participants' General Language Levels.....66

Spanish and Communication in the Community..68

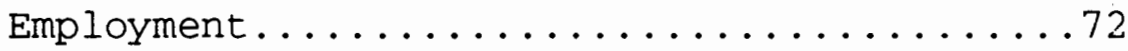

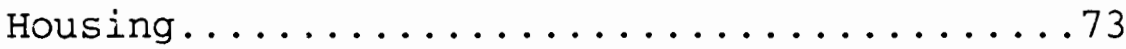

Utilities and Social Services...........75 


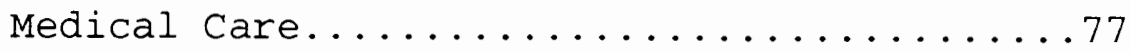

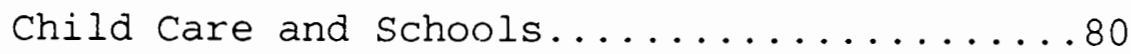

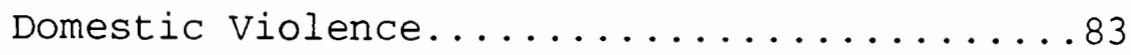

V QUALITATIVE RESULTS: LATINO VOICES..........85

Roles of Interpreters and Translations.....85

Essential Bilingual Services............89

Mutual Communication Efforts of Spanish and English Language Worlds.........93

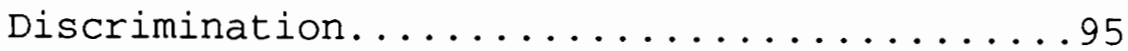

Culture, Language, and Child Care........98

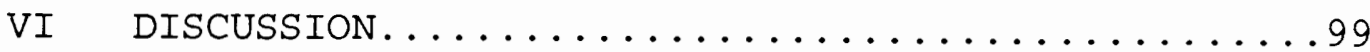

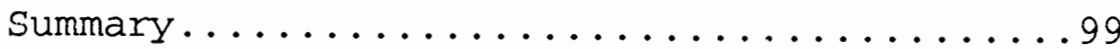

Review

Results

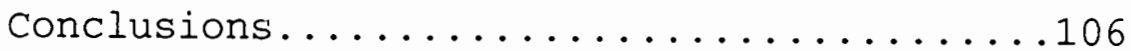

Motifs

Addressing Needs

Domestic Violence

Diversity of Participants

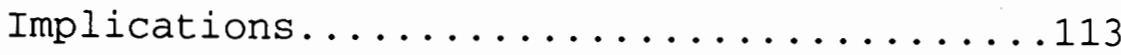

Recommendations

Further Research

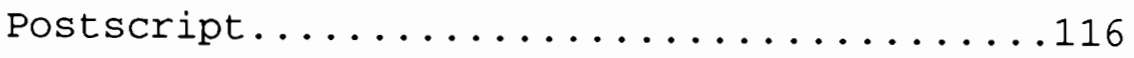

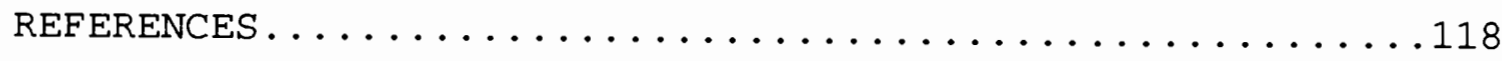

APPENDICES

A QUESTIONNAIRE: SPANISH AND ENGLISH..........123

B COMPILATION OF PARTICIPANTS' RESPONSES TO

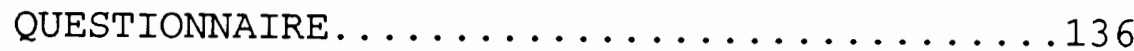




\section{LIST OF FIGURES}

FIGURE

PAGE

1. Participants' Language Abilities...........67

2. Spanish and Communication in the Community.....69

3. Participants' Speech Act and Literacy

Difficulties in English.................

4. Utility Companies and Social Service Agencies....76

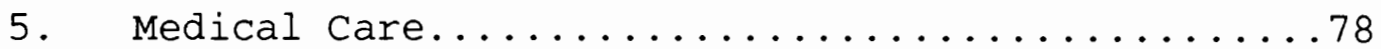

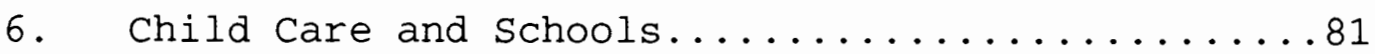

7. Domestic Violence..................... 84 
CHAPTER I

INTRODUCTION

OVERVIEW

The purpose of this study is to describe the linguistic needs of a Latino community in a small city and neighboring town in the Northwest. Focused on are issues that affect bilingual development of recent Latino immigrant families in this community, linguistic and other factors that affect their access to the surrounding community, and the extent and nature of the surrounding community's relations with this Latino community.

Formulation of Research Problem

This research problem was formulated out of observations of barriers faced by this Latino community in the midst of the largely English speaking and mostly Anglo-American culture of the surrounding community, and out of the concern that this surrounding community may be somewhat resistant to adjusting to its changing linguistic, ethnic, and racial demographics. While the issue that inspired the study was the observation of treatment of Latinos by some of the area's police, during the beginning stages of investigation it became clear that this issue was just one of many having to 
do with cultural and linguistic differences. Therefore, a more encompassing focus was taken to look at linguistic and other barriers for Latino families in regards to meeting basic needs and accessing services. To provide the research foundation for this study, a review of the literature was completed focusing on Latino demographics, immigrant experiences, cultures, and acculturation in the United States; the nature, history, and consequences of the Englishonly movement; and multiculturalism and equality of representation in society.

\section{Theoretical Framework}

This study is based on a theoretical framework, as discussed in Skutnabb-Kangas (1990), that all ethnicities, both minority and majority, have the basic human right to define themselves and have that self-definition be respected by others. The position taken is that integration is a dynamic process where change occurs in all ethnic groups and individuals. This is in opposition to the view of integration as an assimilationist process where usually the minority ethnicity is expected to integrate to the "mainstream" ethnicity's cultural, linguistic, and structural norm:

In this view, the immigrant or the immigrant group is seen as the one who has to be integrated into a majority mainstream society, which exists an sich, without being influenced to any noticeable extent by the immigrant....This static and ethnocentric view where the whole burden of integration is on the incomer alone, and 
where the dominant group's values are presented as somehow 'shared' and 'universal', rather than particularistic and changing, like all values are, still prevails in many countries. When the majority population is presented in this way as an integrated mainstream, homogeneously sharing universal cultural values, this characteristic legitimates its access to power and resources. (pp. 86-87)

This study is based on the researcher's belief that mainstream society should not decide what of the minority's ethnicity it may accept and allow to exist as part of the mainstream (e.g., La Bamba, burritos, and "hasta mañana"; cf. The Latinoization of American Culture, 1992) and what it relegates to the "private" sphere (e.g., "the government should not promote ethnic languages"; cf. Trueba, 1979), especially when these private aspects of the majority ethnicity are supported by public institutions such as schools (Skutnabb-Kangas, 1990). Thus, the view forming the framework of this study is that all people are ethnicities with equal rights to exist and have access to power and resources, whether it be access to services, political decision making, or developing societal structures based in cultural paradigms.

\section{Approach}

The approach taken in this study is an insider's view or emic approach (Johnson, 1992), as it is based on data provided by the Latino community only (no data collection was attempted from the surrounding community). Therefore, the conclusions are biased toward the Latino experience. Looked 
at are experiences of recent Mexican and Central American immigrant families. Many of these families, some of whom benefited from the 1986 amnesty immigration program and its family reunification provisions, work in agriculture; others are part of town networks where relatives and others follow earlier immigrants from communities in Mexico to work in urban and nonmigratory agriculture settings (cf. Durand \& Massey, 1992); and some are political and wartime refugees. This Latino community has been growing and stabilizing over the previous decade, and is currently in a period of rapid growth.

Focused on are experiences of Latino families in this community; however, the unit of analysis is Latina mothers, reasons for which are elaborated on in chapter III. Briefly, the researcher was in a position to gather data from Latina mothers rather than from other members of the Latino community because of extensive contact with them and the ensuing development of trusting relationships with many. Moreover, it was observed that these Latina mothers seemed to play a "backbone" role in their families, thereby justifying their representing their families in this study.

\section{Needs Assessment}

Research was undertaken on designing needs assessments. A model for curriculum planning was useful in considering various steps (determine what now exists; determine what is 
wanted; develop a data gathering instrument; collect information; and analyze the data) involved in designing and carrying out a needs assessment (Zenger \& Zenger, 1982). Further research was carried out on needs assessment models used in social services and public policy planning. The following purposes of needs assessments and descriptions of different needs were important in this study's development.

Purposes. The purpose of a needs assessment is to identify problems and solutions and evaluate their importance and relevance (MCKillip, 1987). Before beginning a needs assessment, it must be asked who it is intended to inform or influence, and whose needs are to be assessed (Hobbs, 1987). Purposes may be to politicize segments of the population; testify, as in creating community awareness; produce evidence of contradiction to change cognitions of leaders; advocate for sociopolitical change, as in increasing resource commitment and meeting previously unmet needs; budget, as in establishing priorities; plan, as in making decisions about program planning, development, or implementation; describe, as in increasing understanding for academics; or rationalize the status quo (Hobbs, 1987; McKillip, 1987).

The purpose of this study's needs assessment is multifold and holistic, including aspects of all those presented above, if indirectly, with the exception of rationalizing the status quo. However, its central purpose is to testify towards creating community awareness about this 
Latino community, with the hopes of influencing program planning and development, and increasing resources to meet previously unmet needs.

Needs. Needs assessments evaluate a variety of needs. Following Rothman and Grant's (1987) presentation of types of needs, this study reports on normative needs, as in Latinos not having access to certain established social services for lack of Spanish speaking providers; comparative needs, as in Anglos getting promotions to the restaurant kitchen (versus dishwashing) over Latinos; felt needs, as in most limited English proficiency (LEP) Latinos wanting to improve their English to ameliorate their lives; and expressed needs, as in some Latinos demanding respect for the use of spanish outside the home. The objective in assessing and reporting on multiple needs is a holistic effort towards creating community awareness, further discussed below.

\section{objectives}

The study's immediate objective is to record participants' reflections on and experiences in this society by asking them, as in McKillip's (1987) discrepancy model of needs assessment, to identify what ought to be, determine what is, and deal with discrepancy identification. Participants' responses are used to make recommendations to English as a second language (ESL) programs about relevant material to include in their curriculums, and to social 
service agencies, clinics and doctor's offices, utility companies, schools, interested employers and property managers, and others about improving access for Latinos. As in McKillip's marketing model of needs assessment, the objective of these recommendations is to improve the quality and range of services provided by classrooms and community organizations alike for maximum utilization by the target population, with the ultimate objective of facilitating the surrounding society's positive reception of and adjustment to its changing population.

\section{Methods}

Combined are qualitative case study description and observation in the form of ethnographic style note-taking and short interviews, with quantitative survey methods in the form of a questionnaire. Both quantitative and qualitative research methods are employed because quantitative methods, while useful, establish relationships in a linear fashion, limiting the obtaining of data that reveals complexities of real-life situations. On the other hand, the inclusion of qualitative methods, which are more holistic, increases the obtaining of data that describes the research focus in its real-life complexity (Johnson, 1992). The employment of both quantitative and qualitative methods increases the likelihood of obtaining data that more accurately reflect the multifaceted aspects of the Latino community under study. 
Research ouestions

The following are general guiding questions that began the study and shaped its direction:

A. What have been the immigration and stabilization

experiences of the Latino community?

B. What services does the Latino community have access to?

1. Does the Latino community perceive that these services meet their needs?

2. Which services are bilingual, and which assume a monolingual English population?

3. Does the Latino community think access to more services would be beneficial? If so, to which services? 4. What is effective for services to be accessible to Latinos?

a. Should nonbilingual services be expanded to be bilingual?

b. Should the surrounding community be educated in regards to Spanish and cultural competency? c. Should Latinos be educated as to linguistic and cultural strategies for self-empowerment in regards to living within the surrounding community?

C. What have been the Latino community's experiences with the Anglo community and what is the Anglo community's role in Latinos' lives? 
USE OF TERMS: LATINO

Technical terms are defined as each new term is introduced. It is necessary here, however, to discuss the term "Latino" (Latina, Latinas, and Latinos), which is used throughout the study to refer to project participants, their community, and peoples with Spanish speaking origins in the United states in general.

Diverse minorities are often put into larger and more inclusive groups, despite historical, ideological, biological, and geographical origin differences that may exist between them (Valencia, 1992). The group "Latino" can be defined neither racially nor culturally because it includes peoples with origins as diverse as indigenous peoples with ancestors who came from Asia thousands of years ago, Europeans, and Africans (Shorris, 1992a). Rodriguez (1988) writes:

For generations, Latin America had been the place, the bed, of a confluence of so many races and cultures... In the music of Latin America you will hear the litany of bloodlines: the African drum, the German accordion, the cry from the minaret. (p. 84)

Thus, the use of a single term to refer to a population of such diverse origins and cultures is problematic, as it fails to give recognition to this diversity and becomes, as Shorris (1992b) writes, "a name into which millions disappear" (p. 23). In reality, there are no Latinos, but, Mexicans, Nicaraguans, Salvadorans, Cubans, and so forth, 
diverse peoples who "are not so different that they cannot communicate and not so alike that they have nothing to say to each other" (p. 24).

While it is necessary to recognize that choosing a name to represent these incredibly diverse peoples is problematic, it would be even more so if they had no name at all. Defining this group gives it enough numbers to have a political voice and thus makes it politically necessary to speak of them (Shorris, 1992a, 1992b). The name by which one chooses to identify oneself--Latino, Hispanic, Chicano, Mexican, Mejicano, Mexican-American--is important and may depend on one's view and understanding of history, in particular, upon whether one looks at Latino history as having begun with Columbus' "discovery" of a "New World" or, as Shorris (1992b) writes, with "the emergence of people from the earth in a place called Aztlán" (p. 19).

The term Latino is problematic in that its literal meaning acknowledges only European origins of this diverse group, yet does not include reference to indigenous American or African roots. It is even used to refer to indigenous peoples who may have no connection to Spanish language or culture. Other terms, however, also have their limitations. "Hispanic" means influenced by Spain and can include not only peoples from the Americas and Europe, but also peoples from other parts of the world, such as Equatorial Guinea. Moreover, Hispanic identifies origins in Spanish colonization 
without acknowledging pre-conquest American and/or African roots in Latino cultures. Shorris (1992a) writes:

Hispanic...is an English word meaning, "pertaining to ancient spain....Hispanic belongs to those in power; it is the choice of establishments, exiles, social climbers and kings. Latino has been adopted by almost everyone else. (p. A21)

For the Latino population participating in this study, the term "Mexican" might be appropriate, yet its use would exclude the Central Americans involved. Historically, "Chicano" may be a more likely term, because its origins are indigenous and the populations of Mexico and Central America can be traced to it. However, for many Latinos, including those involved in this study, Chicano has connotations that refer to Mexican people born in the United States, to the exclusion of all historical others. In any case, while Latino is not much better than other terms, it has been adopted by a majority of those it refers to, as discussed by Shorris above, and most importantly by the participants involved, and is therefore used in this study.

The following chapters present a framework, the methodology, the results, and some conclusions. Chapter II reviews the literature towards constructing a framework in three areas related to the project's focus. Chapter III discusses the participants and the methodology used in gathering the data. Chapters IV and V present quantitative and qualitative results from the questionnaire and short 
interviews, respectively. Finally, Chapter VI summarizes the study and provides some conclusions, implications, and recommendations for further research. 
CHAPTER II

REVIEW OF THE LITERATURE

This review of the literature attempts to provide the foundation for a study of the linguistic needs of a latino community in a small city and neighboring town in the Northwest. Although the relation of the chapter's various sections to each other may not present themselves immediately, they are connected in that together they form several important background pieces relevant to the focus of the study.

This chapter contains a discussion of Latinos in the United states, focusing on immigrant experiences, culture, and effects of acculturation on mental well-being. Following, the English-only movement is reviewed, focusing on its nature, history, and some implications of its proposed English Language Amendment (ELA) to the American Constitution. This discussion provides a partial background to the general climate in the United States in the 1980's and 1990 's in regards to multilingual and multicultural issues. The final section contains a discussion of equality of representation in society, including assimilation, ethnic division versus ethnic diversity, language as a resource, the "hidden curriculum", and pluralistic integration. 
LATINOS IN THE UNITED STATES

This section contains a presentation of Latino immigrant experiences, with a focus on obstacles many Latino immigrants face in ameliorating their lives in the United states. Language issues, culture shock, discrimination, and economic difficulties are examined. Following this, the process of acculturation and the often resulting psychological distress Latino immigrants may experience are presented, including contrasts between Latino culture and the dominant Anglo culture.

\section{Latino Immigrant Experiences}

The Latino population, a diversity of peoples, as discussed in Chapter I, has always been an integral part of the United States. In recent decades this population has experienced rapid growth. In 1990, according to the United States Census count, the Latino population was 22 million, an increase of $53 \%$ over the 1980 count (Passel, 1992). While this figure includes many different nationalities and ethnicities, a 63\% majority are Mexican-Americans (Who Are America's Hispanics, 1992). Moreover, of these 22 million Latinos, it is estimated that over nine million, over $40 \%$, are immigrants (Passel, 1992). While this group is diverse, many of the immigrant experiences Latinos face in regards to the dominant Anglo society are similar. 
Language. Learning English is one of most immigrants' primary goals. For many, it is one of the biggest obstacles towards ameliorating their and their families' lives. Immigrants may face economic and other issues in regards to making a life in American society, assuring the well-being of their families, and meeting their basic needs while struggling to learn English (Rimer, 1991).

These survival issues are interwoven; compounded, they often present obstacles for immigrants to pursuing ESL classes. For example, in Hayes' (1989) study of barriers to regular attendance in adult ESL classes, several issues related to lack of economic resources faced by many immigrants were central to Latinos not being able to attend class regularly: lack of time because of employment, lack of transportation, lack of classes located in neighborhoods where many immigrants live, and lack of child care.

Culture Shock. Many immigrants deal with feelings of inadequacy in having limited English communication abilities. Moreover, LEP Latinos may face unaccepting or nonunderstanding aspects of the mainstream population, such as having to deal with Americans who lack patience in conversing in English with LEP people, which may confirm feelings of linguistic inadequacy and give rise to immigrant invalidation (Ishiyama \& Westwood, 1992). Latino immigrants may also have to deal with Americans who actually underestimate the intelligence of people who speak Spanish (Rimer, 1991). 
Ishiyama and Westwood's (1992) writing on cross-cultural counseling and "ethnic clients" applies to the Latino immigrant situation. Discussed are the often difficult experiences ethnic clients have in moving to a foreign culture, involving complex psychosocial adjustment, including culture shock, depression, and homesickness. In addition to dealing with language issues in regards to the dominant Anglo culture, ethnic clients may also have to deal with feelings of invalidation when people from the dominant culture demonstrate "lack of understanding, insensitive manner of communication, and culture-bound perspectives and values" ( $p$. 57).

Liebkind (1989) writes about the process by which humans tend to establish social identity:

We generally try to achieve a consensus with others about who and what we are. The process through which this happens can be called "identity negotiations". In identity negotiations we "present" ourselves in a particular light (self-presentation), which means that we want others to accept our own identity for the other (alter-casting) and are confronted with the selfpresentation and alter-casting of the other. (p. 52)

Considering the identity negotiation process, immigrants' identities may become emotional issues when they have frequent discriminatory experiences and conflicts with others in regards to differences in communication and values (Ishiyama \& Westwood, 1992). 
Acculturation and its Effects on Fsychological Distress and Emotional Adjustment

Acculturation. Acculturation is a multidimensional process of change that occurs when cultural groups have contact, and that may involve changes in beliefs, values, and behavioral practices. Acculturation can be measured behaviorally or attitudinally by measuring cultural awareness (e.g., cultural heritage and preference for language use) or ethnic loyalty (e.g., attitudes related to ethnic identity and pride, and perceptions of discrimination) (Moyerman \& Forman, 1992). While much of the primary focus in studying the acculturation process has been on change occurring in minority groups, change also occurs in the majority group (Kaplan \& Marks, 1990).

Kaplan and Marks (1990) discuss two modes of acculturation, the assimilatory and integratory, focusing on the movement of minorities into the majority. In the assimilation mode, minorities leave their ethnic orientation and move towards identifying with the dominant group. In the integration mode, minorities retain their cultural identity and heritage, leading to a bicultural orientation. Moyerman and Forman (1992) emphasize that a bicultural orientation where both cultures are balanced is optimal for psychological health.

According to Kaplan and Marks (1990), some scholars hold the perspective that minorities who are less acculturated may 
have higher levels of distress than those who are more acculturated; others hold the opposite to be true. In any case, acculturation is not a static but a dynamic process that changes over time. An acculturating individual may become alienated. Yet as time passes, this individual's mode of acculturation may develop towards integration and biculturalism when ties to one's native culture or traditional support base are re-established, contributing to positive psychological health. In recent Latino immigrant communities, imbalances in modes of acculturation combined with a large proportion of young people in initial stages of acculturation may result in high levels of psychological distress.

Latino and Anglo Cultural Contrasts. Latino immigrants in the process of acculturation may experience psychological distress. Crucial to understanding this distress are differences between central aspects of Latino culture and the dominant Anglo culture. Here, contrasts between Latino and Anglo cultures are presented, not for the purpose of valuing aspects of one over the other, but to point out some of the issues for acculturating Latinos facing the dominant Anglo culture.

Traditional Latino values place great emphasis on the family, the community, and obligation to the group (Manoleas \& Carillo, 1991; Kaplan \& Marks, 1990). These values are integrated with what Manoleas and Carillo emphasize as the 
Latino cultural notion of "bienestar", which encompasses the health and well-being of the whole person, including spiritual health, family, and community:

This sharply contrasts with a pathology-focused or problem-oriented approach commonly found in western mental health. The common view among Latinos is that problems are to be addressed within the family system or other natural suport system such as the church. Latino[s]... are often in severe distress before they will seek help outside these support systems. (p. 141) Within the individual, Latino and Anglo cultures also differ greatly. In contrast to the dominant Anglo culture, where achievement, competition, self-reliance, and individualism are emphasized (Kaplan \& Marks, 1990), Latinos tend to strive for interpersonal harmony (Moyerman \& Forman, 1992). In relationships between people, Latinos generally place great importance on showing respect, cultivating mutual trust, and maintaining a friendly environment. Showing respect for individuals, their families, and their beliefs is of primary importance; who people are may supersede other aspects of the individual, such as what they do or know (Manoleas \& Carillo, 1991), which tends to differ from Anglo cultural norms. These differences in traditional values may account for difficulties Latino immigrants may have as minorities functioning and integrating in a new, Anglodominated society.

Latinos and Acculturation. Moyerman and Forman (1992) write that there is a strong relation between higher levels of acculturation and individual distress for Latinos, with 
more reports of addictions and family conflict in the more acculturated. Based on findings from their study of MexicanAmericans, Kaplan and Marks (1990) also report that as acculturation increases, distress significantly increases in young Latino adults. Causal factors of this phenomenon may be that acculturating young Latino adults may encounter alienation and discrimination as they attempt to advance themselves economically and socially in the dominant society, thereby producing psychological distress. Moreover, in thus advancing themselves, young Latino adults may lose their traditional resources and ethnically-based kinship and friendship support networks, adding to this psychological distress.

Manoleas and Carillo (1991) confirm Kaplan's and Marks' position in their discussion of stress faced by young Latino social work students:

[An] underlying conflict for many students is not only the fear that they will not fit into their families or communities of origin as before but also the knowledge that they may never completely fit into the Anglo's social structures unless they undergo a dramatic level of acculturation. (pp. 138-139)

on the other hand, according to Kaplan and Marks (1990), while distress tends to increase with higher levels of acculturation in young Latino adults, distress tends to decrease in older Latino adults. Possible reasons for older Latinos showing less negative effects on mental health, despite high levels of acculturation, are that while they may 
have experienced or still experience discrimination, they are more likely to spend less time in employment situations and thus may have less chance for discriminatory contact. Moreover, older Latinos may have developed a more bicultural orientation than their younger counterparts through a process of re-establishing ties to their native culture. In recent Latino immigrant communities, however, this bicultural orientation is not likely to have been achieved by many.

\section{ENGLISH-ONLY MOVEMENT}

An understanding of the English-only movement may contribute to insight into why the current fear of "outsiders" in United States society is so great. This fear has caused people to actually create potential and real legislation that may affect the lives of minority groups. It is important to have an understanding of how this legislation affects language policy, which has a direct influence on many aspects of immigrants' lives, including access to social services.

This section contains a general review of the history and objectives of the English-only movement. Then, arguments for the movement's proposed English Language Amendment (ELA) are presented. Following this is a brief description of the historical precedence to the English-only movement. Finally, arguments against the proposed ELA and its possible effects if it were to pass are presented. 
History and objectives

The English-only movement began in 1981 when senator Hayakawa of California introduced the first English language amendment to make English California's official language. The movement has as its objective the amendment of the American Constitution to declare English the official language of the United States (Tollefson, 1991). In 1986, California passed a proposition to amend the state constitution to make English the official state language (Trasvina, 1988). Since then, many states have followed California in initiating intra-state debates over whether English should be declared an official language. Some states have gone as far as to pass their own versions of the California proposition, including Indiana, Kentucky, Illinois, Nebraska, Virginia, Colorado, Florida, and Arizona (Tollefson, 1991), the latter three being states, along with California, with proportionally large Spanish speaking populations.

The two organizations behind the English-only movement, English First and U.S. English, have political action committees that raise and donate campaign funds as part of their political lobbying efforts (Trasvina, 1988). These organizations also function as wielders of pressure for the abolition of the use of non-English languages both in public and private sectors of society. 


\section{Arguments for English only}

Activists in the English-only movement argue in favor of declaring English the official language of the United states because they say the status of English is threatened with the recent arrival of many new immigrants. English-only proponents say these new immigrants are not learning English and assimilating as past immigrants have. They also argue that current laws and policies that allow the use of languages other than English encourage cultural divisiveness and do not force non-English speakers to learn English (Judd, 1990). Judd continues:

Such multilingualism has allegedly caused monolingual English speakers to be denied jobs and feel like strangers in their own country. Furthermore, because some current governmental regulations and statutes permit the use of non-English languages, non-English speakers do not bother to learn the common language and thus cannot advance socially or economically. (p. 39)

\section{Historical Precedence}

Throughout its history, the United States has been a multilingual country, from the languages of its native inhabitants to those of its immigrants from all parts of Europe, Asia, and Africa, and its creoles. The American national language, its lingua-franca, has always been English, and this has never been challenged. Only within the last century of United States history has there been any remarkable movement to put pressure on new immigrants to assimilate linguistically more rapidly than the typical 
pattern most immigrants have followed of complete assimilation to English by the third generation (Daniels, $1990)$.

Today's situation of recent immigrants and the reaction against them compares to the situation during the first "great wave" of immigration in the late 1800's and early 1900's. Molesky (1988) writes about this period of American history:

Multilingualism began to be seen as threatening to the welfare of the nation, and English supremacy was increasingly promoted.... [The "nativist" atmosphere associated the English language] with "being American" and "being patriotic." Teaching immigrants to replace their ethnic languages with English only was considered an effective means of inculculating American values. (pp. 50-51)

Following in the steps of the nativists and their reaction to the first great wave of immigration, proponents of the English-only movement demonstrate a similar reaction to today's second great wave of immigration.

\section{Arguments Against the ELA}

Opponents of the ELA argue that an amendment is not needed to assure the continued existence of English as the primary language of the political, social, and economic realm in the United States (Trasvina, 1988; Tollefson, 1991).

Opponents say immigrants do not need to be legally reminded of the importance of learning English, as the waiting lists for adult ESL classes in any major city can attest (Daniels, 1990). It is common for thousands of people to be placed on 
waiting lists or turned away from classes because of the demand. Moreover, opponents of the ELA say most immigrants place great importance on their children learning English. In a survey of Latinos, almost 100 percent of respondents said it was of primary importance that their children read and write English well (Trasvina, 1988).

Some opponents of the ELA say the real debate is not over just language, but over how the acculturation process should proceed in the United States. Geoffrey Nunburg, a professor of linguistics at Stanford University, says the English-only movement "sends a message that [non-English speakers] cannot be trusted to become American like their ancestors did, and their assimilation must be imposed by statute" (quoted in Salholz, Gonzalez, Hurt III, \& Wingert, 1989, p. 23). Other opponents think proponents of the English-only movement are motivated by feelings of economic and social insecurity, and therefore scapegoat non-English speaking people, motivated by a belief that if only these people could be forced to speak English, today's social and economic problems would go away (Salholz, Gonzalez, Hurt III, \& Wingert, 1989).

Immigrants in smaller communities may be even more affected, because minorities are less "invisible" than in larger cities. This is important to look at to gain understanding as to whether institutionalized racism and linguicism are affecting social services for LEP individuals. 
Possible Effects of the ELA

If the ELA were to pass, its effects could be multifold. Daniels (1990) presents a list of some services targeted for abolition by the English-only movement:

[T] ranslators in public hospitals; 911 emergency services; voting materials, instructions, and ballots; court reporters and other legal services; bilingual education in public schools; school materials, parent conferences, report cards; driver's license regulations and examinations; non-English radio and television broadcasting; non-English holdings in public libraries; street signs, park names, commemorative naming of public sites; directory assistance; telephone books and yellow pages; tourist information; public housing listings and information; bus and train schedules and signs; [and] general advertising, business signs, billboards, menus. (p. 6)

Dueñas-Gonzalez (1990) argues against the ELA, stressing that its passage might endanger constitutional rights. Employees might be left with no legal recourse in the face of employers discriminating against non-English speaking employees on the basis of language. In the courts, interpreters and translators might neither be provided nor allowed, which might deny non-English speaking or LEP people the constitutional right to understand the nature of the proceedings, confront witnesses, and have the assistance of counsel. Elections materials might no longer be provided in languages other than English, which might limit the equal participation of United States citizens in elections and discourage voting participation among minorities. In schools, the implementation of bilingual education might 
become illegal, despite research pointing to benefits of teaching content to minority language children in their first language, and an atmosphere of intolerance of non-English languages in schools might be encouraged.

While opponents of the ELA say there seems to be little chance it will pass, as its supporters in Congress are few, the confusion the English-only debate has created on a state level, especially where pro-English-only legislation has been enacted, has caused harm (Judd, 1990). Tollefson (1991) writes about some effects that have been felt in states where English has been declared the official state language:

In Arizona, the state Board of Pardons and Paroles has denied hearings to non-English-speaking prisoners until confusion over the new official English law is cleared up. In Florida, a cashier in a Coral Gables supermarket was suspended from work for ten days for asking a coworker a question in Spanish. (p. 121, cited from Combs, 1989)

Considering these and other incidents that have occurred (cf. Daniels, 1990), and the possible endangerment to citizens' consititutional rights, opponents of the ELA say its passage might create more division and social unrest than unity. This would lead to the opposite effect of Englishonly advocates' stated objective in attempting to prevent people from using non-English languages (Dueñas-Gonzales, 1990; Judd, 1990). For recent Latino immigrants, passage of the ELA might create a vicious cycle. LEP individuals might be less likely or actually prevented from attempting to access social services, hindering bicultural integration. 
EQUALITY OF REPRESENTATION IN SOCIETY

This section contains a discussion of equality of representation in society in regards to ethnicity and integration. Presented are assimilationist and pluralist viewpoints in the United States regarding multilingualism, multiculturalism, and access to power and resources.

An understanding of these viewpoints is critical to identify positions held by individuals in the dominant majority society. This is important because once it is known whether a given position is assimilatory or pluralistic, negative behavior is more easily accounted for, and becomes easier to combat. When ideologies behind peoples can be identified, ideologies behind structures can be identified as well. Moreover, understanding of these viewpoints in individuals contributes to insight into the existence of negative behavior in structures. Negative structural behavior may affect the allocation of funds, and to what extent immigrants and other minorities are served or not.

\section{Assimilation}

One viewpoint in American society today is that recent immigrants have contributed to a lowering of the standard of living for many Americans and are a major part of what is causing a disintegration of society. One of the central points of this position is that immigrants are not 
assimilating to the fnglo-American cultural and linguistic "mainstream". In Dillin's (1992) article, the viewpoints of Pat Buchanan, a participant in the 1992 presidential primary race, demonstrate an assimilationist position. Buchanan holds that an ideal American society of the 1950's is collapsing and being undermined:

All this happened as immigration, legal and illegal, grew and the institutions which could help to assimilate the newcomers were breaking down. The result, he says, was alienation, ethnic gang violence, new demands for ethnic studies and separatism on campuses, and growing pressure to teach children in Spanish and other languages. The cultural fabric of the nation is fraying. (Dillin, 1992, p. 8)

In regards to Latinos not assimilating to Anglo linguistic and cultural norms, an atmosphere of fear is sometimes promoted. For example, in The Futurist, the subheading "Will U.S. be 50\% Spanish-speaking by 2050?" (Latinos on the Rise, 1993, p. 48) is followed by wording that evokes special interest or dangerous floodwater images: "Some 1,000 publications already cater specifically to Latino audiences... Latino businesses themselves are gaining ground" [emphasis added] (pp. 48-49). Sometimes fear is demonstrated in regards to changing ethnicity. In USA TOday, Mann (1984), discussing a "Latin American Threat", argues that increased population growth as a result of continued present rates of immigration will overly strain natural resources in the United states. Yet his final point in support of this position is an ethnic argument against immigration: 
Criticisms of adequate immigration controls, based on civil liberties, have no merit and merely distract attention from the real issues. The alternative is social and economic chaos, coupled with major changes in the ethnic composition of our society [emphasis added], and continued rapid population growth. (p. 11)

Buchanan's and Mann's viewpoints seem to echo the past. The following quotations, reprints from Daniel De Leon's editorials from the early 1990's, were part of the national discussion of "The Immigration Question" during the first great wave of immigration. The first two quotations were from an intra-Socialist Party discussion of immigration and the workforce and were presented as part of De Leon's arguments against them.

Guy Miller, a delegate to the Socialist Party, discussed biological, sociological, and economic issues as part of his anti-immigration stance:

The delegate warned: "Whenever you take any action that puts your sanction upon the efforts of the manufacturer to bring the hords [mark, the 'hordes'] of either Europe [mark, 'Europe'] or Asia to this soil, you take your stand for the lowering of civilization." (De Leon, $1908 a$, p. 2S)

Robert Hunter, also a member of the Socialist Party, argued that the effect of increased immigration and thus increased immigrant birth rates was a decrease in "native" (assumed to mean descendents of earlier European inhabitants of North America) birthrates, implying that this was undesirable:

[Immigrant births] "are supplanting the descendants of the original stock of this country. This is the racesuicide, the annihilation of our native stock, which unlimited immigration forces upon us, none the less powerfully because it is gradually and stealthily done." (De Leon, 1908b, p. 2S) 
Both of these anti-immigration arguments were obviously based on racism and demonstrated their authors' feelings of racial superiority. De Leon (1909) responded:

[In the] United States,...all nations, almost all races, are represented, and in numbers not a few. Let any issue be raised suggestive of degrees in desirability, and the immediate consequence is that, with each of the nationalities now in the land, the latent, long cultivated and interested superstitions of superiority above all other races will forthwith begin to pulsate. The Immigration Question is such an issue. (p. 3S)

Thus, as in Molesky's (1988) discussion of the early 1900's precedence to the English-only movement, antiimmigrationist and assimilationist viewpoints of today also have historical precedence. Knowledge of history of these positions is important to see their roots, and to identify parallel events in the past. With this knowledge, the ability to make more informed decisions about directions for policy making is possible. The relative strength of integrationist or assimilationist viewpoints in individuals and systems influences policy making, allocation of resources, and ultimately, the lives of immigrants and other minorities and their access to services.

\section{Ethnic Division versus Ethnic Diversity: Language as a}

\section{Resource}

Another current viewpoint in the United States is that immigrants have created ethnic tensions, and that supporting ethnicity in effect encourages disunity in the nation. While Buchanan's view that teaching in languages other than English 
is part of a "fraying" of the "cultural fabric of the nation" is perhaps extreme, his objection to teaching children in "Spanish and other languages" is a common position.

Arguments against diversity appear within the vast field of education. For example, regarding maintenance bilingual education, Epstein (cited in Trueba, 1979) holds that maintenance of the first non-English language is a means by which to support ethnic identity, and asks why the federal government should reinforce ethnic identities. Trueba responds by pointing out the perhaps assimilationist viewpoint underlying Epstein's position:

Affirmative ethnicity means to Epstein a governmental policy in support of languages and culture maintenance for linguistic minorities in this country. Perhaps this is precisely what Epstein is afraid of: If the United States permits native speakers of other languages to use their native tongues in this country, they will grow in numbers and influence. He is highly concerned, therefore, that whatever language policy alternative is offered by educators not be federal government, it should not "require giving the native tongue the kind of equal status in the curriculum" enjoyed by the English language. Is Epstein suggesting that we should immerse ethnic children (speakers of languages other than English) in an all-English curriculum; and then, when they have completely forgotten their language, we should ask the federal government for funds to teach them a foreign language? What a waste of federal funds! Worse still, what a waste of human talents. (pp. 437-438)

Trueba considers the languages of students involved in bilingual education as resources, a position that is largely absent from official government policy discourse on bilingual education. For example, throughout Baker's and dekanter's (1981) report (hereafter referred to as the Baker/dekanter 
report) on bilingual education, published by the office of Planning, Budget, and Evaluation of the United States Department of Education as a pivotal paper for policy planning, the first language is referred to only in regards to students' lack of English. In Birman and Ginburg's (1981) report "Addressing the Needs of Language-Minority Children: Issues for Federal Policy," also published by the Department of Education, the term "deficiency" is used frequently to refer to students' language abilities. For example, "children's language deficiencies [emphasis added] differ in their home language and English" (p. 14).

Ruiz (1987) discusses the difference between seeing language as a resource and language as a deficiency as that between "conceiving of ethnic languages as 'problems' and foreign languages as 'resources'" (p. 26). Ruiz holds that foreign language study is seen as an "elite, academic pursuit", a "resource" reflecting the "quality" of education, and related to national security. Bilingual education, on the other hand, is seen to reflect the "equality" of education, a "problem": if the transfer is not made from the first language to English, the potential for national disunity is supposedly more likely. Following this argument, while the Civil Rights Act established that bilingual education is a right through Lau v. Nichols, Ruiz argues that emphasizing maintenance as the means to meet this basic right could provide fuel for those who fear plurality. On the 
other hand, emphasizing maintenance as a resource has the potential to increase its support.

Understanding the language-as-a-problem/language-as-aresource dichotomy allows for insight into how these perspectives affect how language is dealt with in social services and in the workplace. When the perspective that language is a resource prevails, this might mean provision of services in a more equitable way, and fuller use of and respect for diverse language abilities in the workplace. When the dominant position is of larguage as a problem, LEP minorities might be affected negatively in both access to services and employment. Understanding of this dichotomy is important, especially in looking at recent immigrant communities.

Stein (1990) writes that instead of dividing foreign language study from its natural resource of minority language speakers, both quality of foreign language study and equality of bilingual education could be combined rather than treated as separate entities, as they are in most schools. In a model school in New York City, Latino and mainstream students study together alternate days in Spanish and English, and thus both have the opportunity to learn a second language while maintaining and developing skills in their first. Stein continues that a further benefit of this scholastic arrangement is not only shared linguistic resources but 
shared cultural resources, perhaps leading to less rigidity in cultural definitions of what is appropriate behavior.

This model applied to the larger community might translate into less negative or even positive reactions to the provision of social services in non-traditional (nonmainstream) ways. Moreover, it might influence or allow entry of diverse ways of thinking into decision making processes about allocation of resources. How decision making power is used directly affects the lives of minorities.

\section{Hidden Curriculum}

People often assume structures act in the best interest of communities and society. Illich (1970) writes that the "hidden curriculum" in schooling leads citizens to believe that bureaucracies, supposedly guided by scientific knowledge in planning and decision making, are "efficient and benevolent" (p. 74; cf. Santiago, 1982). Structures, however, exist not as objective abstractions removed from subjective influences. They exist, as Berlin (1988) writes in regards to pedagogical structures, as entities within ideological frameworks of "assumptions about what is real, what is good, what is possible, and how power ought to be distributed" (p. 492; cf. Raimes, 1991). These ideological frameworks influence decisions made about contents of pedagogies and other structures. 
Systems may be "efficient" and "benevolent" to bureaucracies, but may not be so to people. Schooling reproduces "national character", thereby putting pressure on those who are "different" to move towards the mainstream. Most people are not conscious of the existence of this pattern, and thus are not aware when belief systems are being taught. People who do not demonstrate national character are sanctioned when they do not fit in; they have not learned these belief systems.

In social service, objectives for results of service delivery fit mainstream beliefs and values. Because people create social service policy, if they have not developed consciousness about the hidden curriculum, they may not be aware of how the policies they create affect people who are different from themselves. Knowledge of the hidden curriculum is important for mainstream social service policy makers and providers to have. Having come through this system, people in social service reproduce what they have been taught, and may not design adequate resources for those whose values and beliefs are not like theirs.

Illich's and Berlin's observations apply to the following discussion of bilingual, refugee, and migrant education policy in the United States. An important piece of the developmental maintenance model of bilingual education versus the transitional and immersion models is that the development of the non-English first language encourages the 
preservation of linguistic and cultural identity, which has been shown to lead to positive academic benefits, including higher academic motivation, higher grade point averages, and lower drop-out rates (Christian, 1982; Curiel \& Richeck, 1986). The authors of the article "Pendulum or Progress?" (Cross Cultural Resource Center, 1981) criticize the position taken by the United States Department of Education in the Baker/dekanter report, in which maintenance bilingual education is not even discussed, in support of immersion bilingual education:

[The authors of the Baker/dekanter report] assert that since a language minority child will require years of work to develop L2 [second language] fluency, it is "unreasonable to expect native-like fluency" (V, 9). From this they conclude that the goal of bilingual education is to be sure that the bilingual child succeeds in English speaking society and that this can be attained by language development "somewhere below the 50th percentile"...The suggestion essentially relegates minority language children indefinitely to the lower end of the academic spectrum. Consider the implications of this suggestion for placement in bilingual programs and for "mainstreaming". If one were to accept a proficiency level "somewhere below the 50th percentile", language minority (LM) children with unacceptably low English proficiencies would be ineligible for special assistance. This is a radical departure from the notion of equal educational opportunity for linguistic minority children. (pp. 9-10)

Following this argument, official government policy on bilingual education acknowledges the likelihood of limited futures for LEP students.

According to Tollefson (1991), a similar situation exists in migrant and refugee language education in the United States. The likelihood of limited employment 
opportunities is implicitly acknowledged in the kinds and levels of language and speech acts taught to prepare refugees and immigrants for employment:

[These language and speech acts are often] part of a broad policy to channel migrants into marginal jobs in the peripheral economy that offer little security and no opportunity to gain additional language or job skills. (p. 104)...The primary goal of refugee education is to reduce the cost of public assistance by forcing refugees and other immigrants to accept low-paying jobs or be declared ineligible for public assistance. (p. 112)

It is important to be aware of these hidden curriculums so as to be able to identify the ideological frameworks that affect other aspects of lives of immigrants and other minorities, such as social services.

\section{Pluralistic Integration}

Skutnabb-Kangas (1990) writes that integration is often seen as the responsibility of the immigrant (i.e., the immigrant must assimilate). According to this viewpoint, the mainstream is somehow already integrated into "its own" society. This position legitimizes the mainstream's access to power and resources. Skutnabb-Kangas continues that minorities are often seen within a "deficiency-framework" where problems they face result from deficiencies in the minorities themselves. This echoes the language-as-a-problem argument discussed above. Problems minorities face are not analyzed in terms of ethnocentrism, linguicism, racism, and discriminatory practices of the majority society. 
Encompassing Liebkind's (1989) identity negotiations (the process of defining the self in society on an individual level), Skutnabb-Kangas (1990) presents a "radical-utopian" phase of integration involving negotiations about the legitimacy of accepted cultural, linguistic, and ethnic features:

[These features] may originally come from any of the groups involved, and...compromises must be sought about them. Since the integration relation is socially created and constructed through interaction between the parties to be integrated, the conditions for this interaction become equally important as objects of study as the actors. If there is unequal access to power and resources in the negotiation process, there is a risk that some features are being forcibly imposed as 'universal' and 'common' to all. (p. 90)

Freire (1973) holds that the traditional educational system is assimilatory: one perspective, that of the mainstream or those in power, defines reality. Contrasting with this is Freire's vision of many perspectives on reality coming together as active creators of history and as constructors in changing the power structure. Stein (1990), applying this vision to a model of bilingual education, writes that Freire's perspective can promote "a kind of pluralistic integration, the equal sharing of diverse languages and cultures in an atmosphere of dialogue" (412). Freire's vision is applicable to structures and systems in American society in general, including social service policy development, decision making about allocations of funding, program planning, and service delivery. 
In conclusion, the United States is made up of immigrants from many countries, languages, and cultures. Assimilationist acculturation experiences often increase mental distress, while integrationist acculturation experiences enourage a mentally healthy bicultural orientation. It is important to be aware whether systems, such as social services, are designed for integrationist or assimilationist experiences to identify positive or negative influences in the lives of immigrants and other minorities. This is especially true for those living within the mainstream in smaller communities where minorities are more "visible". Ultimately, as Young (1991) writes:

The 'global village' will not be created by immigrants everywhere adapting to host societies but only by 'host societies' also adapting to immigrants and both immigrants and hosts moving to a more sophisticated awareness of intercultural problems. (p. 305) 


\section{CHAPTER III}

\section{METHODS}

This chapter presents the methods used in this study. First is a presentation of the project location, project design, and process of gaining entry to potential participants. Following, the participants are described, including the recruitment process and participants' general characteristics. Then, the instruments, the questionnaire and short interview, used in gathering the needs assessment data are presented. Following this is a description of the process used in compiling the questionnaire and interview results. Finally, limitations with the questionnaire, interviews, and participant sample are discussed.

\section{PROJECT LOCATION AND DESIGN}

\section{The Agency}

The site selected for this project was a non-profit social service agency serving low-income Latinos in a small city in the Northwest. Entry was arranged upon discussing the planned project with the two case workers in a program that provides case management and parenting education to Spanish speaking families with young children. It was 
decided that the researcher would provide volunteer case management and program support fifteen hours a week (two days) for three or more months. The objective for this volunteering was to observe clients' (the term the agency's employees use to refer to people accessing services, which will be used henceforth) general linguistic needs and attributes over an extended period, while taking ethnographic style notes, and to identify central themes in clients' lives. However, less than three months into the volunteer period, both of the program's employees left the agency. The researcher was hired as a replacement case worker, and six months later was promoted to the program manager position.

\section{observation}

During the observation period, ethnographic style notes were taken on reasons clients accessed the agency's services, what aspects of the surrounding society proved to be barriers for clients fulfilling their daily needs, and language issues involved in both of the above. Two and a half months, or 150 hours, were spent observing.

Before beginning the observation period, the researcher signed a statement of confidentiality in regards to clients. The objective for this period was to be able to observe during case management with clients' consent without appearing to probe. The researcher stationed herself in the office of one of the case workers as her assistant and worked 
on program support activities. When greeting clients in the lobby, the case worker would ask whether it was acceptable to them for her assistant to be present during their meeting. All clients agreed to this presence. It is possible that clients may have felt pressure to consent; however, clients seemed to have confidence in the case worker and apparently trusted her judgement about appropriateness and confidentiality.

Case management included interpreting and translating, providing parenting education, advocating for clients, providing resource and referral, assessing clients' needs, developing client action plans, administering assistance funds, intervening in crises, organizing and recruiting for trainings and classes, and networking and collaborating with community and social service agencies. As part of the observation period, the researcher worked directly with clients in conjunction with the case worker in a multitude of case management situations, which are elaborated on in the Themes section below. The researcher began to know some of the clients, and they began to know her. Most of the clients accessing the program's services were Latina mothers with young children.

\section{Themes}

In the third month of volunteering, five themes were identified that form the general parameters of clients' 
meeting their basic needs and making a life in this society towards the betterment of their families: Employment, Housing, Access to Services (or Utilities/Social Services), Medical Attention, and child Care/schools. At this time, two more themes were added: Domestic Violence (or Crisis), because this issue is a major player in many clients' lives; and General Language, to find out what clients generally think about their own and the surrounding society's language abilities. These seven themes provided a framework for a questionnaire, which then formed the basis for short interviews.

The themes arose out of case management observed and provided during the extensive observation period, and are based on seeing and listening to clients' experiences and needs. The accuracy of these themes in describing the general parameters of clients' making their lives in this society was confirmed and reconfirmed over the course of the research process, which lasted over one year after the themes were identified. The following are examples of case management situations that led to the identification of these themes. Language issues, the theme General Language, were integral to most situations:

Employment. It was observed that one of the main reasons clients accessed the agency was for help in finding employment. The researcher worked with many clients on searching and learning to use the help wanted section of the 
classified ads, filling out employment applications, and designing resumes, as well as accessing employment programs and agencies. From this arose the theme Employment.

Housing. The researcher observed that many clients accessed the agency for help in housing issues. Some were families without adequate or with no housing, either living with relatives or friends, or homeless. Other clients who already had housing accessed the agency's interpreting, translating, and advocacy services to find more appropriate housing for their family's needs; to communicate with property managers about repairs, complaints, or other issues; and for help in accessing the limited or non-bilingual services at other agencies, such as the county's federal housing agency. The researcher helped clients access temporary family shelters, search and learn how to use the housing section of the classified ads, make telephone calls to prospective property managers, and bridge linguistic barriers with other agencies. The researcher also prepared an informational flyer in Spanish for prospective home owners on low-income home buying. The Housing theme arose from this case management.

Utilities/Social services. It was observed that clients often accessed the agency for help with linguistic barriers in dealing with utility companies and social service agencies, leading to the identification of the theme Access to Services. Utility Companies and Social Services were 
grouped together because of similarities in issues brought to case management by clients (although economics played a larger role with utility companies), and because both seemed to play a similarly involved role in clients' lives. The researcher interpreted for clients to begin utility services; advocated in negotiating with utility companies over payment, cut-off, and complaint issues; and provided information about financial help and economical ways to maintain services.

In regards to social services, the researcher helped many clients fill out forms from other agencies, such as Adult and Family Services food stamp applications and reports. A Latina mother brought in a notice left on her front door by a local private agency to have it translated; the researcher interpreted to make arrangements for the delivery of her child's donated bed.

Case management was provided for an LEP Latino family that had received a letter in English from the federal housing agency warning that they were to be dropped from its housing program if they did not respond within a certain period. When this potentially discriminatory situation was pointed out, an employee at this housing agency responded that they cannot "cater" to every language. Concurrently, another LEP Latino family was being asked to leave one of this housing agency's programs because the family had not followed its rules regarding sanitation (an employee asked if 
this family's lower cleanliness standard was cultural). These regulations were provided in English only.

Medical care. Accessing health care--interpretation, resource, and referral--was another reason many clients came to the agency, and from this observation arose the theme Medical Care. Although the local medical clinic for lowincome people provided services in Spanish one day a week, clients often needed medical services other days of the week, as well. When this clinic hired a bilingual receptionist, some clients reported confusion over crucial information communicated, and expressed doubts about this receptionist's full understanding of Spanish. While several local pediatricians spoke excellent to limited Spanish, the nurses and receptionists in these doctors' offices were monolingual English. The researcher interpreted with receptionists, nurses, and doctors for many LEP Latino families.

During case management, a young, single, Latina mother who was eight months pregnant said she had not had any prenatal care, so the researcher discussed available resources and interpreted to make appointments with local prenatal services. During another case management session, the client said she was miscarrying, so the researcher transported her to the emergency room at the large regional hospital. Hospital staff almost begged the researcher to stay and interpret; the hospital called for bilingual 
volunteers, yet had inadequate bilingual staff, and often provided no interpreters.

child care. Clients frequently accessed the researcher as a child care resource connection in the Latino community. A Latina mother came in looking for someone to care for her children, as the heavy agricultural season was approaching and both she and her husband would be working, so the researcher put her in contact with another Latina mother who was providing child care. Clients also accessed the agency for resource, referral, interpretation, translation, and advocacy in regaras to schools and the federal Head start program. The researcher helped clients determine which schools their children would attend, understand back-toschool mailings, and fill out related applications and letters of recommendation. The theme child care/Schools arose out of this case management.

Domestic Violence. Many Latina mothers spoke of violence situations at home during case management, giving rise to the theme Domestic Violence. A Latina mother called saying her teenage sister had been abducted by the girl's boyfriend. The case worker interpreted when the mother's four year old child the girl had been caring for testified to police about what happened. Another Latina mother, due to give birth three days before, accessed the agency to wait and receive counseling before being transported with her children to a local shelter for battered women. 
This shelter for battered women had no bilingual staff, but relied on bilingual volunteers. Spaces at the shelter had filled, so another Latina mother was housed at a nonconcealed shelter for families. The husband found out where she was; the client called the battered women's crisis line, but no Spanish speaking provider was avaible; confusion arose over where to pick her up, and the husband took her children away. The case worker went with the police as an advocate and interpreter when the children were recovered. Often, multiple issues were dealt with in case management sessions. In the following example, the themes General Language, Employment, Housing, Social Services, Domestic Violence were identified: A single, Latina mother accessed the agency saying two bodies had been found in the park that morning, and her seven year old child had interpreted when the monolingual English police came knocking on doors looking for witnesses. The case worker provided counseling and support. The client's primary issue was to find assistance in making her rental payment; her husband had brought her from Mexico and then deserted her and her three children. The case worker provided referral, interpretation, and advocacy services to access rental assistance funds through other agencies and to negotiate with the property manager about accepting a partial rent payment. An action plan was designed towards finding employment. The family, however, ended up accessing the shelter for homeless 
families. Later, the woman came back to say she had found a co-signer for new rental contract, an Anglo friend of her husband, who said he would also pay first month's rent. Then, however, he said he would not pay, and hit her and her children. According to the client, because he spoke English, the police did not take him away, even when she showed them her bloody mouth.

\section{PARTICIPANTS}

\section{Identification}

This project's needs assessment questionnaire was to have been part of a planned comprehensive needs assessment by the original program manager, which would have included one hundred or more participants. With the cancellation of that larger project and the inclusion of short interviews with the questionnaire, the number of participants was reduced to thirty to make it possible to complete the data gathering process within the limited time frame and resources of this project.

Because most contact with potential participants was with Latina mothers and because the questionnaire was based almost entirely on listening to their experiences and seeing their needs, the questionnaire/interview sessions were carried out with this segment of the population only. Focusing on Latina mothers rather than having a dispersion of 
responses from several segments (e.g., single people, men without their families, elderly people), provides a more indepth study of this important segment of the Latino community.

\section{Recruitment}

Participants were recruited from those women with whom the researcher had developed trusting relationships through case management services. A list was compiled of possible interviewees and contact was made with each to ask if they would be willing to participate in short interviews for a study about language needs. It was clearly stated to each woman that her participation would contribute towards the researcher's personal studies, would hopefully benefit the Latino community in the future, and was not connected with the researcher's provider position (in other words, participation or non-participation would in no way jeopardize or influence case management services).

To obtain thirty participants, contact was made with thirty-seven women. Of the seven with whom interviews did not work out, two did not participate because of the researcher's own time constraints, and five for reasons having to do with basic needs and survival: gathering money to pay the rent; caring for children; and dealing with being homeless, unemployed, and a single mother of three. 


\section{Description}

All participants were recent immigrants to the United States. About one third had arrived within the previous year, about two thirds within the previous three years, and one fifteen years ago. The national origins representation was: one participant from El Salvador, four from Guatemala, and twenty-five from Mexico. This sample represents the diverse origins of Latinos accessing the agency's services, and is a fairly accurate representation of the recent Latino immigrant population in this area of the Northwest, although perhaps slightly heavy on Guatemalans. However, the general experiences of recent immigrants from Mexico and Central America in regards to the surrounding society are similar, i.e., the surrounding society generally does not differentiate in its reception of, reaction to, and treatment of recent Latino immigrants based on whether they are from Mexico or Central America (although Central Americans with refugee or potential refugee status sometimes have more access than Mexicans to the surrounding society via private organizations, such as churches).

All thirty participants were mothers between the ages of 19 and 37, the majority in their twenties, and all except for one had at least one child between the ages of zero and six. The exception, a woman who has a child but not with her, was included within this Latina mother segment because she was caring for the children of her sister, a single mother, as 
her own. The distribution of numbers of children of the participants was: eight women with one child, seven with two children, nine with three children, four with four children, and two with five children. Seventeen participants were living in a neighborhood in the small city with a high recent Latino immigrant population, seven in areas near this neighborhood, and six in the neighboring town connected by a quick bus ride. Most participants were below and a few at or just above the poverty line.

\section{QUESTIONNAIRE AND INTERVIEWS}

\section{Questionnaire Format}

The questionnaire was written in English and translated to Spanish with the help of a native Spanish speaker who is fluent in English. (Copies in both languages are provided in Appendix A.) The questionnaire entries were designed around the seven themes: General Language, Employment, Housing, Utilities/Social Service Agencies, Medical Attention, Child Care, and Crisis (Domestic Violence). The short interviews were based on the questionnaire and carried out during its implementation. These interviews consisted of participants' responses to questionnaire entries beyond the theme-based categories provided, including participants' limited written responses in the "Other" categories and their extensive oral elaborations on their experiences and opinions as inspired by 
the questionnaire entries. Detailed interview notes were taken as participants orally reflected on the questionnaire.

Many questionnaire entries asked participants to respond to theme-related statements on a five-possibility continuum from Excellent to Poor. Other entries were sequence questions asking participants to elaborate on their reasons for answering Yes or No, and what action they usually take if they answer A Little, Not Much, or Never. Several questions asked what language(s) are and would ideally be used in regards to various aspects of participants' lives. Every grouping of questions had an "Other" category for participants to record responses not among those already listed.

\section{Ouestionnaire/Interview Sessions}

The questionnaire/interview sessions consisted of filling out the questionnaire, providing the quantitative results, and copious note-taking as participants discussed experiences, opinions, and observations brought out by the questionnaire contents, providing the qualitative results. A test implementing the questionnaire and short interview instruments was carried out with one participant. Her reactions to the questionnaire entries and content were positive, and her interview responses were rich and detailed. As a result of this test, however, the questionnaire was revised slightly: two questions were added, one to find out 
about participants' first language(s) in the General Language section and the other to make smoother a transition in the Crisis (Domestic Violence) section. Also, it became apparent during this test that participants might have to be guided through the questionnaire to smoothly transition its slightly involved format.

Most participants completed the questionnaire and were interviewed in their homes, and a few in the program office at the agency. Four questionnaire/interview sessions were carried out with two participants together. Each session took an average of one hour, with the shortest lasting thirty minutes and the longest two hours, for a total of thirty hours spent in questionnaire/interview sessions. However, at almost every meeting the researcher ended up doing case management, as well, which extended the average amount of time spent with each participant to two hours. All together about sixty hours were spent with the participants. All interviews were carried out in Spanish.

The questionnaire/interview sessions were scheduled at a wide variety of times during the week and on weekends according to each participant's schedule in efforts to avoid interfering with her family routine, such as picking children up at school, cooking, or caring for children and husbands. For the most part, convenient times were when only babies and toddlers were home, before or after meal preparation, and when husbands were not present. In several cases 
participants chose to make extra arrangements to avoid interruptions, as when one said to her brother-in-law, "Go away, this is women's talk." In two cases, however, participants had the researcher eat dinner with their families before beginning the interviews.

Each session began by explaining the purpose of the questionnaire and interview, and that all information, opinions, and attitudes participants shared would be completely confidential. The questionnaires were coded with the twenty-nine letters of the Spanish alphabet and a star as number thirty. The letter of consent was discussed and it was explained that no responses could be used without participants' permission. All participants signed, several choosing to do so only after the session in order to see its entire contents first.

The researcher attempted to create a somewhat informal mood during the questionnaire/interview sessions because several participants seemed to have "form phobia" (a reluctance to look at or fill out forms), perhaps due to low literacy levels, and because being low-income often entails filling out seemingly endless forms in order to access social services and it was preferable not to add to this burden. Within a few minutes into each session, most participants seemed relaxed and willing to share experiences with little or no prompting. 
Each participant was given the option of reading and filling out the questionnaire herself or of allowing this to be done for her. About an equal number opted each way. However, several began with the reading and filling out being done for them, only to become involved with the process to the point of taking back the questionnaire to do it themselves, even to add their own entry categories to more fully express their responses to certain topics.

During the questionnaire/interview sessions the researcher often sat side-by-side with participants to facilitate their following the questionnaire sequence. Also, if there were any doubt about a participant's literacy or comfort level for dealing with forms, from this position the reading and writing could easily be shared. During one double questionnaire/interview session, the three of us sat close around one end of a table together, one participant saying outright that she was not literate and the other ending up leading the session. This positioning contributed to each participant's comfort with her own abilities during the questionnaire/interview process. In all cases, sitting side-by-side allowed for the easy coding of interview notes according to whatever question the participant was on. 
COMPILING RESULTS

\section{Questionnaire}

The questionnaire results constitute the study's quantitative results. The number of responses for each of the questionnaire's entries was counted and recorded. A few stronger responses were recorded as "1+" to capture their intensity, as when one participant said, "Directions on medicines are in both Spanish and English, but more in English", or when another created her own category, "Never" (stronger than "Poor"), to more accurately express the lack of communication with her child's teachers. In several sections a few participants chose no responses, although they did discuss their experiences. In these cases the researcher followed her notes and chose an appropriate response to fit participants' oral descriptions, if possible. For example, the response "Family" was chosen to describe a participant's child care provider according to her statement: "No one does child care for me, but sometimes my husband stays with the children so I can go to ESL class". Otherwise, unmarked sections were left blank.

While there were a total of forty-eight possible sequence questions to respond to, many participants chose to answer both yes and no (or good and not good) to certain entries and so responded to both sequence groups, more than forty-eight questions. Participants did so as a way to 
express different aspects of their lives, especially to reflect the two communities, the inner and the outer, they live in. For example, in response to the entry, "In general, I feel free to use spanish to communicate [in this city]", some participants addressed the world of family, friends, and places where spanish is frequently spoken (e.g., a neighborhood school, certain social service agencies), and the world outside of this. Thus, tabulations for many questionnaire entries show more than 30 responses for the 30 participants.

\section{Interviews}

The data obtained from the interviews while participants orally responded to the questionnaire constitute the study's qualitative results. The notes taken during the interviews were recorded, paraphrased, translated into English, and edited. Redundancies in participants' responses were eliminated.

Then, the interview responses were reviewed in an effort to identify general categories into which to group participants' experiences, opinions, and observations. The categories that revealed themselves are based on participants' general positions and viewpoints in regard to interpreters, language, and living in this society. 
LIMITATIONS

The following is a brief discussion of several limitations with the questionnaire, interviews, and participant sample. Recommended changes in the questionnaire are also put forth. Finally, alternatives are presented as to viewing these aspects only as limitations, but as possible attributes, as well.

Questionnaire and Recommended changes

Possibility for confusion. The questionnaire's structure from one sequence group to another may have been slightly confusing for participants, because it may not have been immediately clear which questions to respond to. In a few instances participants responded to questions that did not apply to them, and several questions that should have been responded to were left unanswered. With guidance, however, most participants had no difficulty. Moreover, the necessary physical proximity to participants to facilitate this guidance may have encouraged a feeling of interaction and mutual participation, which in turn may have led to more elaboratation on responses and illustration of experiences than otherwise. Thus, instead of creating problems, the slight difficulty of the questionnaire actually may have contributed towards obtaining richer interview responses. Recommended changes. It is recommended that several changes be made in the questionnaire if it is to be used as a 
model for further research. First, to eliminate possible sources of confusion, the two negative past hypothetical conditional questions (questions $24 \mathrm{a}$ and $27 \mathrm{a}$ displayed in Appendix A) should be revised to avoid inaccurate responses. second, alternatives should be developed to the "I Don't Know" category to encourage uniformity in the detail of participants' responses. Third, it is advised that open ended questions precede each section's focus on linguistic issues to encourage the likelihood of obtaining spontaneous responses from participants before focusing on language detail. Finally, a question about written material that comes home from school, and vice versa, should be included to directly address this ongoing communication, instead of asking about language issues at the initial access period (questions 37 through 39 shown in Appendix A) only. (Participants did discuss ongoing written communication with schools during the interviews.)

\section{Interviews and Participants' Lives}

Partipants' Homes. The potential lack of privacy in doing interviews in participants' homes as opposed to in the program office posed a possible problem in regards to the presence of husbands and adult male relatives. First, case management experience had shown that with men present, women frequently did not voice their opinions as readily or independently as without, and it was undesirable for this to 
be an influential factor in participants' responses. Second, the Domestic Violence section posed a potentially difficult situation for some participants if men were around to hear their responses; therefore, this section was made optional so participants could conveniently skip it for this or other reasons.

During the actual questionnaire/interview sessions, the Domestic Violence section with its optional component did not seem to pose a problem. Moreover, the presence of men seemed to have been an influential factor during one interview only. The participant had enthusiastically requested to be interviewed, but upon arrival at her home, the husband was present and the participant seemed reserved. After clarifying that no naines would be attached to the responses, both of them appeared to relax, and after he moved into another room, she seemed open in her responses. In another session with a husband present the opposite occurred; he became interested in the interviews and contributed his own responses along with his wife's. The exchange between the two may have actually encouraged richer interview responses than otherwise.

Two Participants Together. In four of the sessions, two participants chose to be interviewed together for various reasons, including culture, confidence, personality, literacy level, form phobia, and convenience. In three of these double sessions, one participant of each pair did not know 
the researcher as well as the other and seemed more comfortable being interviewed together with her friend or relative. Also, in two of these sessions, one participant was either not literate or seemed to have form phobia, so the presence of another participant helped boost confidence. The fourth of these sessions had been scheduled with one participant, and upon arrival at her home the researcher found another potential participant visiting; the two chose to be interviewed together, perhaps for convenience. Interviewing two participants at a time could call into question the accuracy of their responses, as together they might be more likely to influence each other. On the other hand, richer results may have been obtained by allowing women to participate together. In Latino cultures, problem solving is often not an individual activity, but one involving family members, friends, and community. Culturally, participants may have felt more comfortable being interviewed together, which actually may have led to fuller development of responses, additional elaboration on personal experiences, and more accurate information than if interviews with these eight women had been carried out individually.

\section{Participant Sample}

Because the study's data was collected from a participant sample specific to this Latino community, the study has no external validity with other Latino and/or 
recent immigrant communities. Also, the participant selection process may also have presented a limitation. Participants were not randomly selected, but chosen from those Latinas with whom the researcher developed trusting relationships.

While this non-random selection may present limitations to the results, it can also be argued that these trusting relationships improved reliability. Attempts to obtain random samples from Latino communities with large recent immigrant populations can be difficult, as in the experience with the 1990 Census, where Latinos may have been undercounted for reasons such as Latinos living in multiple or extended family situations against housing regulations or without immigration documents may have avoided being counted. In this regard, these trusting relationships may have allowed for greater access to the Latino community and may have improved the reliability of the results.

The following two chapters present the questionnaire and interview results. The quantitative results from the questionnaire appear in Chapter IV, and the qualitative results from the interviews appear in chapter $V$. 
CHAPTER IV

QUANTITATIVE RESULTS: QUESTIONNAIRE

This chapter presents the study's questionnaire results as the quantitative component of the study, and the following chapter presents the interview results as the qualitative component. Here, the questionnaire results are presented as general statements about participants based on their responses, and about similarities and differences in responses, with limited elaboration based on participants' experiences.

\section{QUESTIONNAIRE ENTRIES}

Many of the questionnaire entries gave participants response choices on a continuum of yes to no (YES!, Yes, Don't know, No, NO!) or excellent to poor (Excellent, Very Good, OK, Not Too Good, Poor). Other questions asked participants to identify speech and literacy acts relevant to their experiences, to choose Spanish, English, or Spanish/English to describe language aspects of their lives, and to select statements that illustrate their reality. Also, all sections included the category "Other" to allow participants the option of recording aspects not included in 
the questionnaire. Spanish and English language copies of the questionnaire are included in Appendix $A$, and the compilation of questionnaire responses is in Appendix B. No verification of the accuracy of participants' responses was attempted, namely because the study"s objective was an emic report on participants' opinions, attitudes, and experiences.

\section{PARTICIPANTS' GENERAL LANGUAGE LEVELS}

Figure 1 presents participants' responses in regards to their language abilities. Participants responded similarly for the most part in regards to their language backgrounds and abilities. One participant speaks Mixe as her first language and twenty-nine speak Spanish, with a few having grown up with grandparents speaking an indigenous language. In regards to participants' Spanish levels, the majority (26 responses, $86 \%$ ) said their oral and aural communication skills in spanish are excellent or very good. Similarly, most participants (24 responses, $80 \%$ ) said their abilities in reading and writing Spanish are excellent or very good. In both oral/aural and literacy skills some participants (four responses, 13\%, each) said their abilities are oK. (Several participants seemed to have low impressions of their oral Spanish skills, perhaps due to concepts about "proper" or 
Oral/aural English: Not so good/Poor OK

Excellent/Very good

Reading/writing English: Not so good/Poor $\mathrm{OK}$

Excellent/Very good

Oral/aural Spanish: Excellent/Very good OK

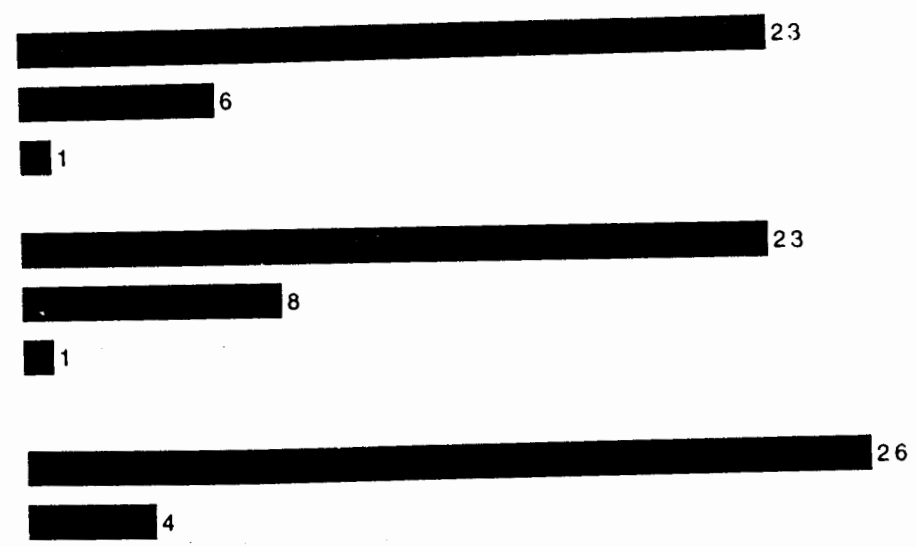

Reading/writing Spanish: Excellent/Very good OK

Not so good/Poor

Eigure 1. Participants' language abilities.

*Number of responses does not always total 30, because several participants responded twice to certain questions. Reasons for this are explained in chapter III. 
"educated" Spanish.) Two participants said they have low or no levels of literacy.

In regards to participants' abilities in English, the majority (23 responses, 77\%) said their oral and aural communication skills are not too good or poor, one fifth (six responses, 20\%) said their skills are ok, and one said her skills are excellent. Participants' reading and writing skilis in English are similar to, although slightly lower than, those for oral and aural communication, with the majority (23 responses, $72 \%$ ) saying their skills are not too good or poor, one fourth (eight responses out of 32) saying their skills are ok, and one saying her skills are very good. Two participants separated reading from writing and provided two responses to this question to more accurately reflect their higher reading levels. On the questionnaire the four skills of reading, writing, listening, and speaking had been condensed into two questions about oral/aural and literacy levels for each language for simplification purposes. These two participants carefully made the distinction.

\section{SPANISH AND COMMUNICATION IN THE COMMUNITY}

Figure 2 shows participants' responses in regards to Spanish and communication in the community. Participants were divided as to feeling free to use Spanish in the community, with many (21 responses, $62 \%$ ) saying they feel comfortable and quite a few (13 responses, 38\%) saying they 
Participant feels free to use Spanish in this community: Yes

No

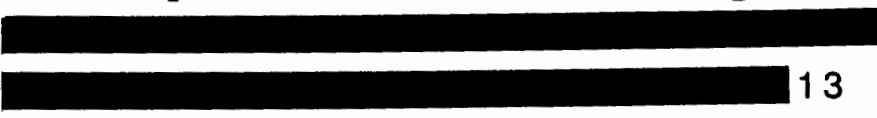

Participant feels free to use written spanish in this community: Yes

No

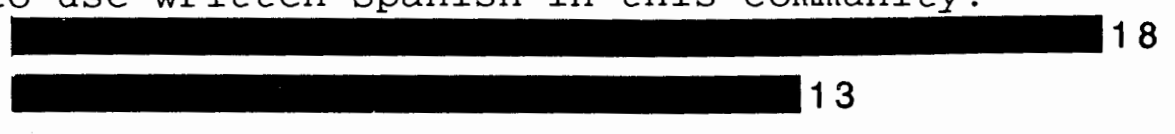

Ability of others in this community to communicate with participant in spanish: Excellent/Very good Not so good/Poor $\mathrm{OK}$

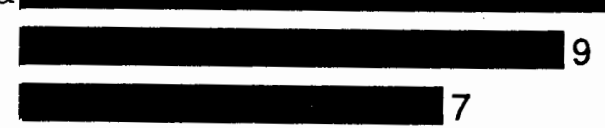

Useful written materials in Spanish are available in this community: No Yes

Don't know

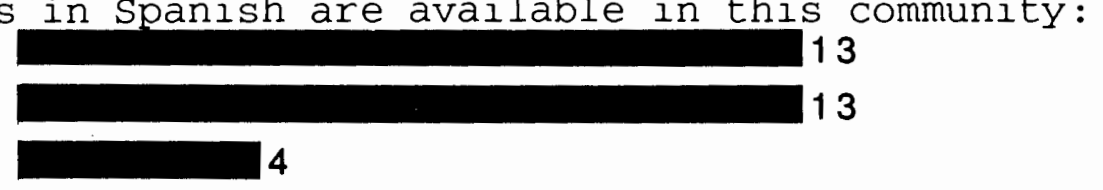

Employers value participant's Spanish: No

Yes

Don't know

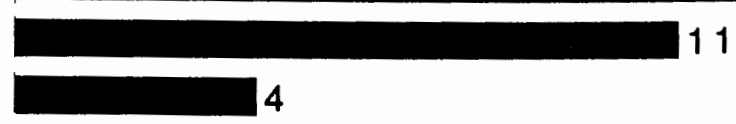

Participant's Spanish helps in finding housing:

No

Don't know

Yes

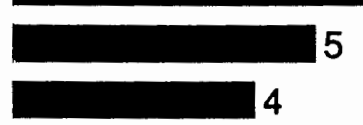

Figure 2. Spanish and communication in the community.

*Number of responses does not always total 30, for reasons explained in Chapter III. 
do not. Several participants responded twice to this question to more accurately reflect the two communities they live in, as discussed above. The results for participants using written Spanish in the community were similar to those for spoken Spanish, with a little over half (18 responses, 58\%) saying they feel free to use written Spanish and nearly half (13 responses, 42\%) saying they do not.

In regards to participants' reflections about the community around them, about half (15 responses, 48\%) said the ability of people to communicate with them in spanish is excellent or very good. However, several participants qualified their responses saying this is limited to areas participants tend to frequent, in particular places where there are Spanish speakers (i.e., friends and bilingual professionals). Some participants (nine+ responses, 29\%) said the ability of people in the community to speak with them in Spanish is oK, and some (seven+ responses, 23\%) responded that this ability is not so good or poor, Participants said these responses of oK, not so good, and poor, over half of the total responses, refer to the outer world of English speakers. In regards to the availability of useful written materials in Spanish, participants were equally divided with almost half saying there generally are useful materials available and another almost half saying there are not (13 responses, 43\%, each). 
In regards to employers valuing participants' Spanish, over half of the participants (18 responses, 55\%) said employers do not, while one third (11 responses, 33\%) said they do, more for their oral and aural communication skills (eight responses) than for their reading and writing skills (two responses). Responses were also mixed according to participants' employment experiences: employers who are Spanish speakers value employees' Spanish, but employers who do not speak Spanish do not. Several participants said some employers value their employees' Spanish because the employers themselves are trying to learn it. A few participants saia some employers value bilingual but not Spanish monolingual employees, and one went so far as to say: "If you have two languages you're worth four people [to employers]; if you have only Spanish you're not even worth one person."

In regards to using Spanish in finding rental housing (all participants rent but one) and dealing with property managers, most participants (21 responses, 70\%) said their Spanish does not help at all. Participants elaborated on problems that arise with the language barrier, from filling out forms to negotiating the check-off list for apartment conditions. Several said they often use their bilingual elementary school age children as interpreters with property managers. The few who said their Spanish language abilities do help (four responses, 13\%) added that these abilities 
allow them to access bilingual social service providers who then help in the housing search. However, despite the role of language barriers in looking for housing, the major issues participants discussed were economics and discrimination.

\section{EMPLOYMENT}

The majority of the participants (23 responses, $74 \%$ ) said it is difficult to find and maintain employment, and about one fifth (six responses, 19\%) said it is not. One participant responded both yes and no to this question to differentiate between finding and maintaining employment, i.e., it is hard to find employment but easy to maintain a job once you have one. Those who responded that finding and maintaining employment is not difficult stressed that their English language abilities helped them, in particular in asking questions (four responses) and understanding (four responses). These participants also discussed the influence of one's character, one's past job experience, and Spanish speaking employers on having positive employment experiences. For participants who responded that it is difficult to find and maintain employment, this difficulty has most to do with the following English language issues: employment applications (18 responses), English as a job requirement (reading/writing 18 responses, oral/aural 15 responses), asking questions (17 responses), giving/receiving instructions (16 responses), written materials in skill 
building courses are in English (16 responses), and talking on the phone (15 responses). Figure 3 provides a graphic representation of these employment speech act and literacy difficulties. In addition to language difficulties, one third of the participants (eleven responses) also discussed other issues contributing to the difficulty in finding and maintaining employment: discrimination against Latinos, lack of work documents, more people looking for employment than there are jobs, and discrimination against women.

\section{HOUSING}

A majority of the participants (23 responses, 77\%) said it is difficult to find housing. English language issues that contribute to this difficulty are: housing applications (19 responses), asking questions (17 responses), negotiating with property managers (16 responses), and understanding (16 responses). Figure 3 also displays these housing speech act and literacy difficulties. Several of those who said it is not difficult to find housing (four responses, 13\%) mentioned that sometimes they do ask for the help of an interpreter. Most participants said issues besides language are major barriers to finding housing: high rents, limits on the number of people allowed to live in one dwelling, requirements (good credit, references, cosigners, and income levels), discrimination against families with children, and discrimination against Latinos. 


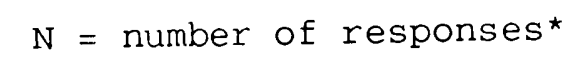

Employment speech acts:

Ask questions

Give/receive instructions

Job requirement

Talk on the phone

Understand

Skill building courses in English

Negotiate

Employment literacy:

Employment applications

Job requirement

Skill building course materials in English

Job listings

Classified ads
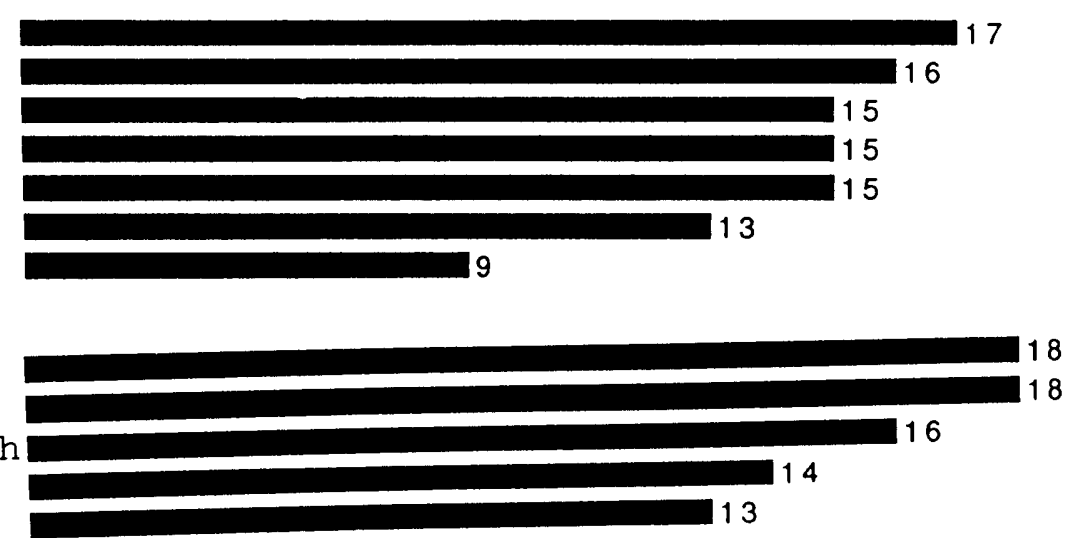

Housing speech acts:

Ask questions

Negotiate with landlord

Understand

Talk on the phone

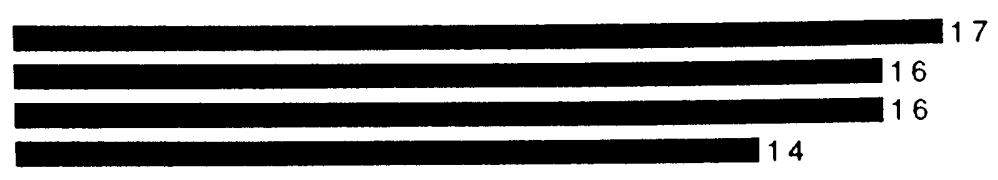

Housing literacy:

Housing applications

Classified ads

Housing announcement board

Eigure 3. Participants' speech act and literacy difficulties in English.

* Number of responses does not always total 30, because several participants responded twice to certain questions. Reasons for this are explained in Chapter III. 
UTILITIES AND SOCIAL SERVICES

Figure 4 presents participants' responses in regards to experiences with utility companies and social service agencies. Most of the participants (21 responses, 70\%) said they had not had problems with utility companies. A few (four responses, 19\%) said their English skills had helped them avoid problems, whereas the majority (13 responses, 62\%) said language had nothing to do with it, but paying the bills on time did. However, for the just under one third of the participants (nine responses, 30\%) who reported having had problems with utility companies, most (six responses) said they would not have had these problems if companies had Spanish speakers, or enough Spanish speakers to meet the demand, in their customer service departments.

Participants were divided about difficulty in accessing social service agencies, with half (15 responses, 50\%) responding that it is difficult and almost half (14 responses, 47\%) responding that it is not. Of those who have had difficulty accessing social sevices, most (12 responses) said they would not have had these difficulties if agencies had Spanish speaking providers, or enough Spanish speakers to meet the demand. Of those participants who said they had had no problem accessing social services, only three said their English skills had helped them avoid difficulty, and most (11 
Participant has had problems with utility companies:

No

Participant's English skills have helped in avoiding problems:

No

Yes

Don't know

Yes Yes

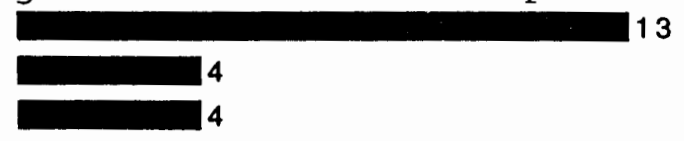

Participant has had difficulties accessing social service agencies:

$$
\text { No }
$$

Participant's English skills helped in avoiding difficulties: No

Yes

Don't know

Yes

Participant would not have had problems if agencies had bilingual providers: Yes

Don't know

Don't know No

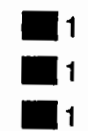

Figure 4. Utility companies and social service agencies.

*Number of responses does not always total 30, because several participants responded twice to certain questions. Reasons for this are explained in Chapter III. 
responses) said the agencies they have accessed have Spanish speaking providers so access is not a problem.

\section{MEDICAL CARE}

Figure 5 displays participants' responses in regards to language issues surrounding their medical care. None of the participants reported that they had not looked for medical care because of language barriers. Twenty-nine participants receive or have received medical care, and one has not needed to. In regards to the language of the medical care participants have received, about half (16 responses, 48\%) said it has been bilingual, about two-fifths (13+ responses, $39 \%$ ) said it has been in English, and a few (four responses, 3\%) said it has been in Spanish. Quite a few of those who reported having received spanish or bilingual medical care said that either the doctor's level of Spanish is not good, or that the doctor speaks Spanish but the nurses and receptionists do not, which thus limits their overall access to quality medical care.

In communicating with the doctor, one third of the participants (10 responses) said they always understand or understand most of the time, another third (10 responses) said they understand sometimes including the important things, and the final third (10 responses) said they understand a little but not the important things or never. Thus, despite over half of the participants responding that 
Language of care:

Bilingual

English

Spanish

$\mathrm{N}=$ number of responses $*$

Participant and doctor can communicate:
Always/Mostly
Sometimes
A little/Never

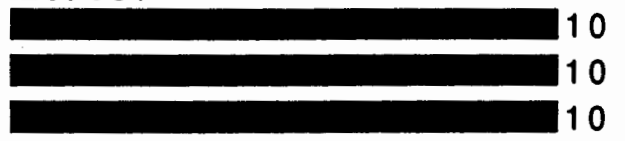

If Sometimes, A little, or Never (above), participant uses following strategies: Finds an interpreter

Tries to understand

Guesses the meaning

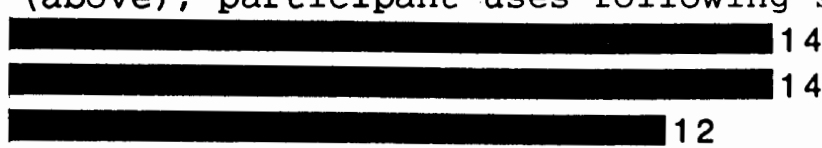

Language of instructions written on medicines: English

Bilingual

Spanish

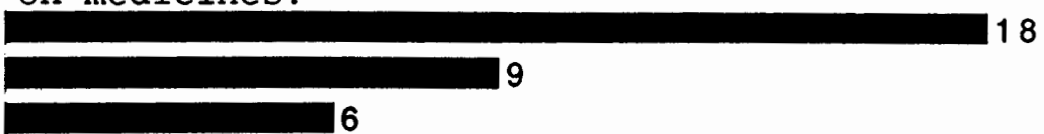

Understand instructions written on medicines: Sometimes

Always/Mostly

A little/Never

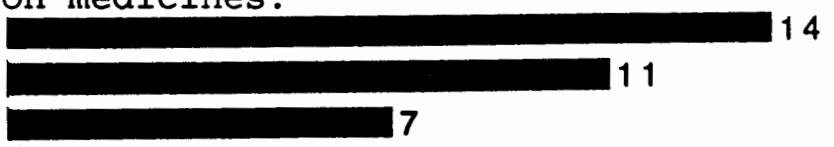

When written instructions (above) in English, partıcipant uses following strategies: Finds a translator

Follows the directions

Relies on memory or guesses

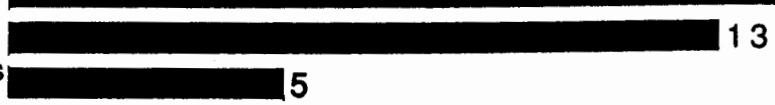

13

Eiqure 5. Medical care.

* Number of responses does not always total 30, for reasons explained in Chapter III. 
they have received medical care bilingually or in Spanish, just one third reported good communicatation (i.e., that they understand most of the time or more), and two thirds reported that communication is lacking (i.e., that they understand some of the time or less). These two thirds deal with the lack or partial lack of communication with their medical care providers by doing the following: finding someone to interpret (14 responses), listening and doing their best to understand (14 responses), and guessing the meaning of what is being said (12 responses).

In regards to medical directions on prescription and over-the-counter drugs, over half of the participants (18+ responses, 55\%) said they are in English only, several (nine responses, 27\%) said they are bilingual, and a few (six responses, 18\%) said they are in Spanish. In regards to participants understanding these directions, whether in English, in Spanish, or bilingual, under half (14 responses, about 44\%) understand these directions sometimes including the important things, one third (11 responses, about $34 \%$ ) always or most of the time, and about one fifth (seven responses, 22\%) a little but not the important things or never. When the instructions are in English, most of the participants find someone to translate (25 responses), many follow the directions themselves (13 responses), and a few rely on their memory of what the doctor said or guess the meaning (five responses). 


\section{CHILD CARE AND SCHOOLS}

Participants' children fall into the following age groups: 19 have babies (baby, as defined by the participants, meaning infants to two year olds), 15 have preschoolers, and 14 have kindergarteners or school age children. Over half of the participants (17 responses, 55\%) said it is not difficult to find child care, not because of participants' abilities in English, but because of the high availability of child care providers within the Latino community. One third of the participants (10 responses, 32\%) responded that it is difficult to find child care because of English language issues, especially giving and receiving information (seven responses), understanding (seven responses), talking on the phone (six responses), and dealing with information in English about child care centers (six responses). However, whether or not finding child care is easy, almost all participants said it is difficult to pay, thus limiting access to child care.

Figure 6 displays participants' responses in regards to provider and language issues concerning child care and schools. Most of the participants obtain child care through friends (18 responses) and family (16 responses), many through Head Start (13 responses) and the school district (12 responses), and one at a child care center. The question concerning participants' abilities to communicate with their 
Child care providers: Friends

Family

Head Start

School district

Child care centers

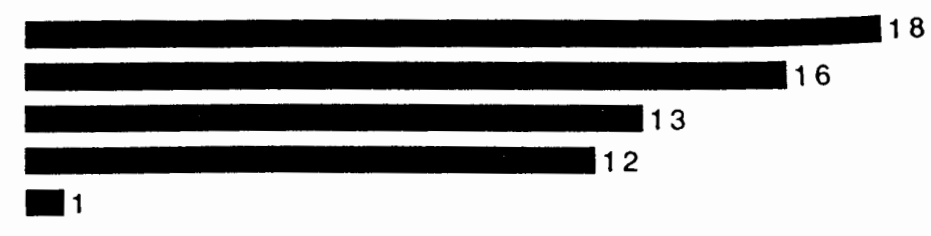

Language of communication with provider:

Spanish

English

Bilingual

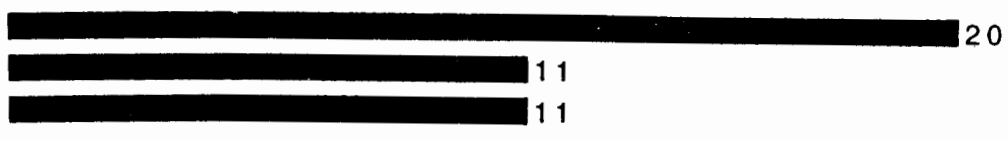

Participant's ability to communicate with provider: Excellent/Very good OK

Not so good/Poor

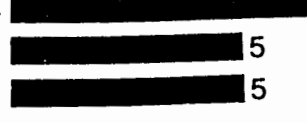

Provider's ability to communicate with participant: Excellent/Very good Not so good/Poor

OK

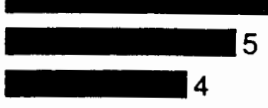

Language of ideal child care center/school: Bilingual Spanish English

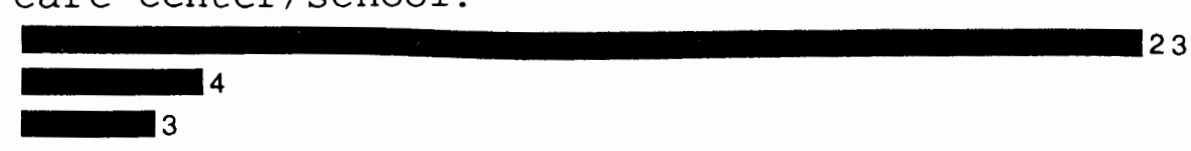

Eigure 6. Child care and schools.

* Number of responses does not always total 30, because several participants responded twice to certain questions. Reasons for this are explained in Chapter III. 
child care providers or their children's teachers elicited 42 responses from the 30 participants, the highest number of responses of any questionnaire entry, perhaps showing both the diversity of their experiences in this area and their concern with this issue. About half of the participants (20 responses, $48 \%$ ) said they communicate with their child care providers in Spanish, reflecting the large percentage of friends and family involved in child care; about one fourth $(11+$ responses, $26 \%)$ said they communicate in English only; and about another fourth (11 responses, 26\%) said they communicate bilingually. Many added that in regards to communication with teachers at Head start and in the school district, whether the communication is bilingual, in spanish, or in English, they often rely on an interpreter.

Participants' ideal child care center or school would be bilingual (23 responses, 77\%), with a few preferring spanish only (four responses, 13\%) or English only (three responses, $10 \%)$.

The majority of the participants (24 responses, $71 \%$ ) said their ability to communicate with their child care providers and children's teachers is excellent or very good, with some reporting that communication is ok (five responses, 15\%) or not so good or poor (five responses, 15\%). Likewise, participants said the ability of most of their child care providers and children's teachers to communicate with participants is excellent or very good (25 responses, $74 \%$ ), 


\section{CHAPTER V}

QUALITATIVE RESULTS: PARTICIPANTS' VOICES

The following is an amalgamation of participants' interview responses. Chosen are experiences and opinions that participants voiced most frequently combined with specific descriptions. Participants' responses are grouped into the following themes: 1) the roles interpreters and translated materials play in participants' lives; 2) what bilingual services participants think are essential, and what can happen and has happened without them; 3) efforts of Spanish and English language worlds to communicate with each other; 4) participants' experiences of discrimination in the community; and 5) the importance of culture and language in participants' accessing child care. Participants' responses are put together as one voice and expressed using first and second person pronouns to illustrate the multifaceted aspects and experiences of Latinas in this community.

\section{ROLES OF INTERPRETERS AND TRANSLATIONS}

Interpreters help us access social service agencies, take care of business with utility companies, get better health care, follow and participate in our children's 
schooling, and more. We feel more comfortable speaking in Spanish than in English. We can use our Spanish language abilities with interpreters, and this is a positive part of our lives in this community.

We often rely on interpreters, especially bilingual social workers and friends, to help meet basic needs, such as accessing housing and free food boxes. Translations help us prevent confusion, for example, as in the announcements from my child's school that come with spanish on one side and English on the other. Interpreters often help us resolve or avoid potentially dangerous situations; for instance, when the directions on medicines are in English, it is riskier to guess or rely on our limited English skills or remember what the doctor says, and safer to find someone to translate. Also, in my domestic violence situation my bilingual friend helped me by calling the police.

Sometimes, however, relying on interpreters to help bridge the language barrier is not the best situation. Communicating through a middle person is not as accurate or efficient as communicating directly because interpreters cannot say everything we want to say in the manner we want it said. Thus, a middle person, while crucial when the one who has power to take decisions in my case (e.g., the social service worker, medical care provider, school teacher, or property manager) speaks no Spanish, can also limit the quality of communication. Optimally, the one with power to 
take decisions in my case is also bilingual, thus eliminating the need for a middle person; however, even in this case, depending on this person's bilingual skills, problems can also arise.

Sometimes a bilingual service lacks in quality because the skills of the interpreter or bilingual worker are not appropriate for a given situation. I have been to the hospital several times when a cleaning person, not a medical professional, was the intermediary between me and the medical care provider. As another example, my eight year old child interprets for me when the bilingual utility employee is not available. Moreover, some interpreters and bilingual workers' Spanish makes us feel sorry for them; we must guess what they are trying to say. The limited Spanish of my child's teacher is the medium for communication during our parent-teacher conferences. The doctors who operated on my husband spoke some Spanish but not much. Often, bilingual doctors' Spanish is not sufficient to explain what I have; they say, "Perhaps you've got this, perhaps you've got that", and then they ask how to say a particular word in Spanish. It gives me a feeling I am not getting competent, quality medical care.

In addition to problems for quality interpretations, sometimes translations or access to translations are inconsistent where bilingual services are provided. A school with a high percentage of Spanish speaking students often 
sends bilingual information and letters home to parents, yet just as often information is sent in English only. The medicines provided at my medical clinic sometimes have directions in Spanish but sometimes do not. At another clinic directions on medicines are in both languages, but they are available only if I ask for them. I went for several months without knowing this because the service is not openly offered. At this same clinic the patient registration forms are partially bilingual: the directions for filling in one's name, address, and phone number are in Spanish, but not the important health history information. Finally, although written informative materials in Spanish are often available in the community and at social service agencies, some of these are in inaccurate Spanish or provide inadequate information and cannot be used.

A given agency, school, or company may have bilingual employees, but perhaps not enough to meet the demand, or their presence may be irregular. For example, often when I call the utility company the Spanish speaker is not in and I am told to call back later, but I do not know if later means after lunch or after the employee is back from vacation. The situation is similar with social service agencies. Sometimes the Spanish speaking worker I am familiar with is suddenly transfered or no longer employed and I am at a loss as to what to do. For example, the Spanish speaker at Head Start left, so I am in trouble now. Also, an agency, school, or 
company may have bilingual workers, but often not in every department. For instance, once when I was current on my utility bill, field workers from the company hung a sign on my door saying they had restricted my service. I understood the sign but was unable to negotiate to let them know they were mistaken.

often we are limited in our access to certain services. For example, we do not have access to just any clinic, only the one that has Spanish speaking doctors once a week, and sometimes this doctor is not even available for this limited time. Other times we may have a Spanish speaking doctor, but the nurses and receptionists speak only English, thus limiting our access to and the quality of our medical care. In an emergency there can be problems for limited English proficiency people, as in dialing "911" and just knowing how to say, "Help!" While the Department of Public Safety has access to Spanish speakers, it takes several minutes to be hooked up with the Spanish telephone line, and by that time I could be dead.

\section{ESSENTIAL BILINGUAI SERVICES}

We need bilingual teachers, schools, and child care centers for better communication between teachers, students, and parents. If there are many Spanish speaking children and only a few Spanish speaking employees, how can a school adequately provide for the needs of these children? My 
ability to communicate with teachers directly is poor or nonexistent; neither is sure the other has understood. I can only communicate with my child's ESL teacher, who speaks Spanish. When I look for child care I ask if any teachers speak Spanish so I can discuss issues concerning my child with them, such as medical information. Having Spanish speaking teachers is important so I can find out how my child did and if she slept or had any accidents. Instead the teachers just say, "It's OK". I have not accessed child care here because there are no Spanish speakers in this area's centers.

With bilingual schools we parents would receive school information in Spanish. This information is very important and needs to be in Spanish. I cannot work on the school parent/child packets with my child because they are in English. When I get an important notice from my child's school, I do not have an interpreter at home, nor do I have time to run to a bilingual agency every time I need something translated. I ask my 8th grader to translate papers that come from school. With bilingual schools our children will grow up knowing both languages. I sent my child to a bilingual school in another city and I was able to work with her on the parent/child packets; moreover, she was learning Spanish along with English. There are no such schools here, and so our children will not only not learn but will forget Spanish. 
All people have the right to receive social services. The need is urgent for more bilingual people at social service agencies to improve access for Spanish speaking people. Every agency should have bilingual people instead of us often having to find an interpreter. Presently, communication is a big problem, and frequently when we arrive at an agency no interpreter is available, so we have to wait or come back another time. Once when I was at the welfare office the Spanish speaking worker was out to lunch, so I helped a vulnerable Spanish speaking woman because the receptionist spoke no spanish. The receptionist said, "Mi español pobre", and I said, "My English, too". Also, sometimes the agency personnel do not have the cultural capacity to work with Latinos.

The need is also urgent for more bilingual people at utility companies and in the community in general. If my bilingual husband were not present, I would have problems communicating. Once I was not able to explain why I could not pay my utility bill on time, so I did not tell the company. I often ask my eight year old son to interpret and translate, for example when the manager wants me to sign something and I need to know what it says before signing. He reads pretty well.

It is urgent that doctors' offices hire bilingual people. My child care provider cannot make an appointment with the doctor because the receptionist speaks only English, 
and my daughters could be dying. I cannot communicate with the doctor, and when I am at the doctor's office sometimes I guess what the doctor says, truly, I feel around. Sometimes doctors give me medicine for an illness my children do not have because of the lack of communication, and often I do not take my children to see the doctor because of the language barrier. Specialists and dentists speak English only. My husband has work injuries and has trouble understanding the physical therapist. I have to provide an interpreter to communicate with the doctor, and this is difficult for me if my bilingual husband is not around. What if I have an emergency? My oldest child interprets and then I understand.

In the hospital everything is in English. I had an operation and no one was there to speak Spanish, and I did not know how to ask for one with the little English I had. I had a complicated delivery, our baby was in incubation for a week, and even with such a critical situation the hospital did not provide a Spanish speaker. I imagined the doctors telling me my husband has died and me just nodding, smiling, and saying, "Yes" for lack of understanding.

It is urgent that directions on medicines be put into Spanish and be openly available for Spanish speaking patients. When the directions are just in English I do not understand the important parts. I gave the medicine my Spanish speaking doctor had prescribed to my infant for several days without understanding the directions on the 
bottle, relying solely on memory for the dosage amounts. A friend of mine gave aspirin to her baby, who then went blind in one eye. The mother could not read the directions or warnings on the bottle and did not know not to give a large dose to her child.

\section{MUTUAL COMMUNICATION EFFORTS OF SPANISH AND ENGLISH LANGUAGE WORLDS}

For many Spanish speakers a major obstacle to having a better life is not being able to speak English. It is good to experience another culture, but difficult to have to work and get along well in English first in order to live here. Having the ability to communicate in English is crucial for us because one does not get ahead without it.

In housing, it is difficult to ask what expenses are included, what happens if I do not pay the rent on time, and whether the entire deposit is refundable. We sometimes say "Yes" when we really do not understand or need more explanation but have difficulty asking questions. In employment, receiving instructions without being able to ask for further clarification is a problem, for example: "I understand I am to put away the dishes, but where and in what order?" When I started at the hotel I understood the supervisor to say I would work three hours each day, but at the end of that time they said I still had more rooms to clean. I had not made other arrangements to pick up my son 
at school, but did not have the negotiation skills to let them know it was not because I was lazy that I needed to go. It is important for us to gain English skills to help us relate with the outer world and maintain stability for our families.

We use our English communication skills to ameliorate our lives. I would like to talk at work but it is difficult for me; my listening is better than my speaking in English, and in conversation I do not want to appear uncouth so I remain silent; however, when I really need to I can get out enough English to convey my meaning. Once my son arrived at Head start crying and I had to explain to the teacher that he does not like to get up in the morning. It took a while to make myself understood, but I did it. My English ability in asking questions really helped during my employment interview. My English skills have helped me a thousand times to avoid problems with utility companies. Once I used my English to lower a long distance telephone bill because I have always been a good customer. Moreover, one has got to be able to give and receive instructions in English, otherwise one cannot boss anybody around.

We do our best to learn English. When the directions on medicines are in English I look in the dictionary and try to learn the important things first. Now I recognize rental applications, and can read rental signs and some housing annoucements. I understood English in particular when I did 
not want to lose the house we are buying. In communicating with doctors, I open my ears wide to understand. I take ESL classes.

For us, speaking Spanish is natural because it is our mother tongue. Some people here do not like us to speak Spanish because they do not understand--they leave. My employers, on the other hand, like the way we speak. They ask me about and try to speak my language. My supervisor admires my Spanish and values it because I try to communicate with her and others at work in her language. She sometimes uses an English-Spanish dictionary to find words I do not know in English and because she wants to learn. For example, one day she said, "Good morning" and wanted to know how to say that in Spanish; the next day she said, "Buenos dias". If more employers would value and learn Spanish they would communicate better and receive better work performance from their Spanish speaking employees. My doctor and I also teach each other words in each other's language.

\section{DISCRIMINATION}

When we speak Spanish in the street people stare at us. Sometimes when I speak Spanish and there are Americans around I feel intimidated, as if they are going to turn around and give me a dirty look. Often, English speakers have no patience with Spanish speakers. When a representative from the phone company called, I understood everything she said 
and responded. She understood me, too, because when I told her my husband speaks better English she rudely hung up saying she would call back when he was home. We had been communicating just fine, and I felt bad about her rudeness and lack of patience.

One gets more respect with English. In looking for housing, property managers cannot as easily say there is nothing available to one who speaks English. I was discriminated against as a Spanish speaker when I went to the store to get my WIC (a nutrition program for low-income pregnant women, infants, and children) milk. When the employee said my coupons were not enough and she needed to see my identification card, which I had forgotten at home, my husband pretended he did not speak English, and she became rude and did not give us the milk. Then I spoke in English and she became nice and gave it to us. It is good to know English so when people insult us we understand; otherwise, we just say, "Thank you" without knowing we are being insulted. Finding housing is difficult because of racial and ethnic discrimination. Property mangers tend to say there is nothing available, reject an application, or not even give out an application when they see Latinos applying. Discrimination is a big factor; there is only one Hispanic family in this big apartment complex in this neighborhood heavily populated with Latinos: us. Then, when we are accepted for housing the discrimination does not stop: the 
manager gets on us for every little thing but is lax with the Americans about having pets and loud music. The manager got mad at just the Mexican children when he found garbage in the parking area, but the American children were just as responsible. The same thing with biking on the sidewalk, he told the Mexican children not to but said nothing to the American children.

Finding and maintaining employment is difficult for us because of discrimination against Latinos. Some employers are racist and treat Latino workers like slaves. Moreover, it is hard for those without work documents because employers yell at them and make them work faster than they possibly can. There are no Hispanic professionals here; Hispanics do not have good jobs. It is difficult for me to find a job that does not end--I always get agricultural jobs--because I am not from here.

Many employers do not like it when we speak Spanish; they think we should speak English. One who speaks English will get a job before one who does not, and may take a job away from one who does not speak English. The supervisor at work made comments that created unnecessary divisions between us Spanish speaking workers based on our English abilities; these were just comments, but they had an influence on how we were treated. At my job there is another Spanish speaking woman and we converse, naturally, in Spanish. My supervisors, however, have told me not to speak Spanish, even 
though it does not affect my production performance; no one is told not to speak English on the job. This issue about speaking Spanish has even been included in my periodic evaluations, upon which possible raises are based. While neatness and steady output are important in production, I am surprised that my supervisors think making sure not to speak Spanish is important.

\section{CULTURE, LANGUAGE, AND CHILD CARE}

My child care provider, a friend, and I understand each other perfectly because she speaks my language. There is more confidence and trust between us, the same people with our common language, than with other people. Only one particular friend do I trust completely to do my child care. I leave my children with relatives with confidence. My sister provides my child care, I do not trust anyone else because of the possibilities of child abuse. It is easy to find child care amongst us Spanish speakers. There is a bigger Latino community here now than before; without this it would be difficult to find child care. It is a given that Latinos do my child care and no one else. 
CHAPTER VI

\section{DISCUSSION}

\section{SUMMARY}

This chapter contains a review of this study's research problem, objectives, and methods, followed by a discussion of the results. Then, conclusions are drawn based on these results. Finally, some implications of the study are discussed, including recommendations for further research.

\section{Review}

Research Problem. The focus of this study was to assess the linguistic needs of a stabilizing and growing Latino community in a small city and neighboring town in the Northwest. This research problem was formulated out of observations of barriers faced by this Latino community in the midst of the surrounding community, which is largely English speaking and mostly Anglo-American. Research questions concerning linguistic and other factors affecting the access of recent Latino immigrant families to the surrounding community, issues affecting these families' biingual development, and the surrounding community's relations in regards to integration with this Latino 
community guided the study. Questionnaire results reinforced how linguistic and other barriers for Latino families impact basic needs and access to services.

objectives. The study's objectives sought to record participants' reflections on their lives in this society, including their experiences, needs, and thoughts about what is and what ought to be. These responses have been used to make recommendations about material relevant to participants' lives to include in ESL program curriculums. Participants' responses have also been used to make recommendations to community members and organizations, including doctor's offices, clinics, and hospitals; schools and child care centers; social service agencies and utility companies; and interested employers and property managers, about ways to improve the quality and range of services. Finally, the overall objective for these recommendations has been to help facilitate the two-way integration of both the Latino and surrounding communities.

Methods. The study was carried out at an agency serving primarily monolingual spanish or LEP low-income Latinos. The researcher was an active participant-observer in the study, first as an agency volunteer and then as a staff case worker in a program serving Latino families with young children. Participants were 30 Latina mothers who were identified and whose recruitment was carried out based on trusting 
relationships the researcher developed with them from the position of service provider.

Research included quantitative and qualitative methodologies: observation, ethnographic-style note-taking, theme identification, survey-questionnaire, and short interviews. Ethnographic-style notes were taken focusing on the reasons Latinos accessed the agency's services. From these notes, central themes in the lives of people in this Latino community were identified. A questionnaire was designed based on these themes, and short interviews were carried out based on and concurrent with the implementation of the questionnaire. The interviews sought to record participants' needs, problems, attitudes, opinions, and ideas about their lives in this community.

\section{Results}

The study's research questions are reiterated with a full discussion of the study's results below. It must be noted that these results do not reflect Skutnabb-Kangas' (1990) two-way integration model, presented as the theoretical framework for this study in Chapter I, because they demonstrate a disparity in regards to access to power and resources.

What have been the immigration and stabilization experiences of the Latino community? Participants' immigration and stabilization experiences generally have had 
to do with barriers of economics, language, and discrimination for participants and their families in ameliorating their lives. Lack of family wage jobs, housing, accessible medical care, and affordable child care have presented economic barriers that hinder or prevent this amelioration from proceeding.

Participants listed the following language-related aspects as key issues in their lives. Lack of bilingual services in social service agencies, utility companies, schools, and especially health care have created difficulties, sometimes critical, for most participants. Participants generally have had more problems with monolingual English employers and property managers, and more positive experiences with bilingual employers and property managers. Participants also have felt the need and wished to improve their English, but often have encountered obstacles to doing so. Obstacles, largely related to economics, have included lack of affordable child care, transportation, and time because of employment. These obstacles parallel those observed by Hayes (1989), presented in Chapter II, for Latinos attending adult ESL classes regularly.

Discrimination issues participants have experienced include discrimination against speaking Spanish on the job, in stores, and in the street; discrimination against race and ethnicity in regards to housing and employment; and some discrimination against families and women in regards to 
housing and employment, respectively. These experiences have contributed to difficulty for participants in ameliorating their lives, including increased distress while working towards the daily well-being of their families in a new culture and society. These results confirm the observations of Rimer (1991) and Ishiyama and Westwood (1992) discussed in Chapter II.

What services does the Lat ino community have access to? Participants responded that in general they have had access to many services, including utility companies, social service agencies, and some doctors, clinics, and hospitals. Notably, while many participants responded that they had not had difficulties receiving services from social service agencies and utility companies (responses displayed in Figure 4 on page 76), during case management the researcher has spent a good portion of her time helping clients access other agencies by interpreting and translating.

Participants said some of these services have met their needs and others have not; generally, language and economic issues were central to this discussion. According to participants, some services have assumed a monolingual English population, in particular hospitals, clinics, and doctor's offices; and some social service agencies. However, more services than not have provided bilingual access for Spanish speaking and LEP Latinos, including private, public, and government agencies. 
Despite this availability, participants responded that often these bilingual services have been insufficient for the following reasons. Not enough bilingual employees may be available to meet the demand, the specified bilingual person may have inadequate Spanish skills, or the barrier of a monolingual English receptionist may prevent access to the needed bilingual service.

Participants responded that access to more services would be beneficial to their families and to the Latino community, stressing the need for more bilingual health care, affordable child care, and bilingual schools, including teachers and written communication from school administrations. Participants said that for services to be accessible to Latinos, effective strategies would be for more people in the surrouding community to become bilingual and to gain deeper cultural understanding. Nonbilingual services should be expanded to be bilingual, and more quality bilingual and culturally competent employees should have positions at all levels of service provision, including doctors, nurses, receptionists, public school teachers, and counselors. In this regard, participants said having an interpreter as a middle person in service provision is often not sufficient for quality access. Participants also said they themselves have been and need to continue learning English towards empowering themselves in regards to living within the surrounding community. 
What have been the Latino community's experiences with the Anglo community and what is the Anglo community's role in Latinos' lives? Participants have experienced difficulties with the Anglo community in regards to housing, employment, and language. According to participants, these experiences have their roots in economics and discrimination against Latinos. High rents, especially for large families needing two or more bedroom dwellings, combined with minimum wage jobs and the lack of affordable child care have created often desperate economic situations for many Latino immigrants. Discrimination by employers, property managers, and other members of the surrounding community have made for negative initial acculturation experiences and have hindered Latino families ameliorating their lives. These results confirm those in studies by Kaplan and Marks (1990) and Manoleas and Carillo (1991), discussed in Chapter II.

On the other hand, participants also said they have had positive experiences with members of the surrounding community. Notably, these have been in regards to Anglos speaking or attempting to speak Spanish and sharing their English, employers in particular. However, according to participants, the Anglo community's role in their lives has remained in the outer realm of employment, schools, and services, and has not entered the inner realm of the family. Notably, child care, which has affected most other aspects of participants' lives, the outer realm (e.g., having or not 
having employment) in particular, has remained part of the family and Latino community inner realm. Almost all participants expressed the expections, assumptions, and hopes that Latinos should be the ones to provide their child care.

\section{CONCLUSIONS}

The researcher suggests several conclusions based on this study's results. Among the most powerful themes to emerge from this study was the motif of the inner and outer communities. Another central motif was the holistic nature of the study, its various parts joining together like pieces of yarn in a tapestry, paralleling the diverse yet whole nature of the Latino community and Latino cultures. Following this, conclusions are presented in regards to the researcher's responsibility to address participants' needs, the various types of needs that emerged during the study, and the importance of addressing these needs in multiple ways. Then, of critical importance yet not adequately assessed in the study, the domestic violence theme is reviewed. Finally, the diversity of participants' backgrounds and possible effects this may have had on the results are discussed.

\section{Motifs}

Inner and outer communities. A motif of inner and outer worlds runs through this study, the privateness of the family and the Latino community contrasted with the public realm and 
the surrounding community. This motif appeared in particular in regards to relations with and the role of the surrounding Anglo community in the Latino community, and especially in looking at child care. For the researcher, the trusting relationships that developed between the researcher and the participants were instrumental to the success of the data gathering process, contributing towards assuring the sincerity of responses. It appeared to the researcher that, although Anglo, she was not perceived to be part of the outer realm, but had entered the private inner realm.

Holistic Nature. A holistic motif was central to the study, appearing and reappearing in the multiple and interconnected themes like a tapestry woven from various threads to create a whole. For example, in the questionnaire, some participants provided "opposite" Yes and No responses to reflect the inner and outer worlds, instead of showing just one part of their reality by choosing a single response. The study itself employed quantitative and qualitative methodologies woven together. This assured the obtaining of more complete results than if just one method had been incorporated. Had quantitative methods been used exclusively, this holistic view would likely have eluded being recorded. This motif also reflects the non-linear, holistic nature of Latino culture (cf. Manoleas \& Carillo, 1991). 
Paralleling the multiple and interconnected needs assessed, the recommendations for addressing these needs discussed below suggest multiple and interconnected ways to address them. It is impossible to isolate participants' needs from one another; accordingly, it is ineffective to attempt to address these needs individually. For example, barriers surrounding finding housing are inseparable from discrimination, minimum wage jobs, high rents, and limited English skills. Participants' limited English skills are interconnected with the lack of affordable child care, transportation, classes located in neighborhoods where participants live, and time due to employment.

\section{Addresssing Needs}

Kellerman (1987) asks whether those practicing needs asssessments have a responsibility to concern themselves with getting needs assessments addressed as well as expressed; the researcher believes she has a responsibility to the participants to do so. Results from this study have been shared with ESL programs, agencies, and other community organizations.

Types of participants' needs assessed were not isolated to one kind or another, but are varied; accordingly, these needs might be addressed in various ways, as well. For example, coming back to Rothman's and Grant's (1987) categorization of needs, reviewed in chapter $I$, the normative 
needs that revealed themselves have implications that social service agencies should address. Access issues in regards to services that are not or only incompletely bilingual, in particular, have legal implications for those agencies receiving government funding.

The comparative needs that emerged, as in discrimination by members of the surrounding community against Latinos in regards to housing and employment, might be addressed by educating and encouraging self-education amongst these individuals. These comparative needs might also be addressed by examining the Latino community's access to resources and power and by making changes to facilitate equal access. This could be undertaken along the lines Skutnabb-Kangas (1990) lays out, as discussed in chapters I and II.

Participants expressed felt needs, as in the need to speak English to ameliorate their families' lives in the daily struggle for survival in the surrounding community. These needs might be addressed in ESL programs by including relevant material towards helping participants move in the direction of their goals. Existing services should be adjusted to make them better fit clients' felt needs, and ways of facilitating participants expressing and finding solutions to these needs could be developed. Also, as Skutnabb-Kangas discusses, to remedy unequal access to power and resources, the surrounding society should engage in 
dialogue and negotiation on equal footing with the Latino community and gain lingual and cultural competency.

The expressed needs that emerged could be addressed by facilitating participants' self-empowerment in addressing these needs. For example, participants demanded that spanish speaking and culturally familiar people from the Latino community do their child care. The provision of funding for a child care cooperative to be designed, organized, directed, and staffed by members of the Latino community would help address both economic and cultural issues in regards to child care. Support for such a cooperative would have implications reaching into other aspects of the lives of Latino families, such as employment and bilingual competency.

Based on case management experience, it is recommended that participants' needs be addressed holistically, as opposed to linearly or separately, so as not to isolate interconnected needs from one another. For example, in an effort to address multiple needs, a holistic collaboration was begun between the researcher's program serving low-income Latino families, the ESL program at the county community college, a county agency providing resources and connections for child care providers and those needing child care, a public elementary school in a neighborhood where many clients live, and a preschool program housed in that school. The collaborative's objective was to improve access to adult ESL classes for clients who otherwise had had difficulties 
attending regularly, including some who had lived in the community for up to seven years without having been able to attend classes because of barriers similar to those Hayes (1989) discusses, as presented in Chapter II. Towards surmounting these barriers, classes were offered in the neighborhood school to address the lack of transportation and lack of classes located near where clients live. Funds were raised to provide culturally competent, quality child care in the preschool space next to the classroom to address the lack of affordable child care. The collaboration was an overwhelming success, with excellent class attendance and notable improvements in clients' English skills in just one term.

\section{Domestic Violence}

While domestic violence is a key issue for many Latino families, for the purposes of this study, not a large number of participants responded that there had been violence in their homes (about one fourth, the results for which are displayed in Figure 7 on page 84 ). It is likely a number of participants did not respond to this question. However, from case management experience, the researcher knows that more of the participants have lived with domestic violence.

The researcher offers several hypotheses to explain this lower response rate. These are based on experience and conversations with other case managers working with victims 
of domestic violence. First, participants may have chosen not to report the existence of violence in their homes for reasons of privacy or shame. Second, participants may not have identified the term domestic violence with what may occur in their homes. These individuals may not have named the violence towards them as a crime; they may not know that they do not have to put up with being hit. Third, participants may have lacked consciousness that what occurs at home is violence, perhaps considering it fate. It is important to note that these points are true for women around world, depending not on culture, ethnicity, race, or social position, but on societal patriarchy.

The objective for the inclusion of domestic violence in this study was primarily to find out if language issues were barriers to getting help, and if getting help was impeded by low quality or non-bilingual services. While no participants reported that they had been impeded in their efforts to find help, language and trust, based on cultural and linguistic understanding, were crucial in their reaching out.

\section{Diversity of Participants}

Participants' ages, countries of origin, and length of time living in the United States were diverse, and may have affected the results. It is the researcher's position based on case management experience and familiarity with the population that this influence was slight, considering that 
most participants were facing similar issues in making their lives in the surrounding society. All participants were from "developing" countries, all came from south of the United States border, and all were Spanish speaking. Moreover, according to the researcher's observations, the surrounding society's reception of and interaction with recent Latino immigrants have not shown much differentiation in regards to diverse backgrounds. However, participants' education levels and immigration status may have influenced the results, as these are issues that might have brought about significant differences in participants' immigrant experiences.

\section{IMPLICATIONS}

The implications of this study are a series of recommendations that concern: 1) economics; 2) bilingual and cultural competetency, discrimination, and integration; and 3) ESL curriculum content. Finally, suggestions are made for further research.

\section{Recommendations}

First, to ameliorate their lives and help families stabilize, participants responded that above all they need affordable child care and housing. Jobs that pay only minimum wage or close to it were often discussed as leading to problems with utilities, as well as preventing access to child care and housing. The high cost of child care combined 
with low wages was cited by over one third of the participants as a major barrier. Similarly, for over one third of the participants, high rents combined with low wages were barriers to finding and maintaining housing, especially for families with more than one or two children and/or with extended family living with them. More resources need to be committed towards affordable housing and child care. The implications of the minimum wage and today's cost of living need to be evaluated, perhaps to lead to a raising of the minumum wage.

Second, participants said they need and would benefit from more bilingual services, especially in medical care and schools. The need for cultural competence on the part of the surrounding community was implied in participants' responses, especially in regards to housing and employment. Members of the surrounding community--employers, landlords, utility and social service employees, health care workers, public school employees, and others--should move towards bilingual and cultural competency.

To truly be effective, a primary goal for improving bilingual services and cultural competence on the part of the surrounding community should be to decrease experiences of discrimination and increase two-way integration of both communities. The overall objective should be to increase equal access to resources and power, according to the 
integration model discussed by Skutnabb-Kangas (1990), presented in chapters I and II.

Third, participants would benefit from the inclusion of particular speech acts and literacy skills, especially those having to do with employment and housing summarized in Figure 3 (on page 74), as components in ESL program curriculums. Also, linguistic and cultural strategies for living within the surrounding community should be taught and practiced.

\section{Further Research}

The results from this study suggest several directions for further research. First, the researcher recommends a focus on domestic violence in the Latino community for future research. Second, research might be undertaken to look at ways diversity in the Latino community affects participants' immigration experiences. Such a study ought to included participants' education levels and immigration status. Third, the researcher recommends that a study be undertaken in the surrounding community to look at attitudes about and experiences with the Latino community in regards to Latino cultures and Spanish language. Such a study should include employers, property managers, utility company employees, social service workers, doctors, receptionists, teachers, child care providers, and other members of the surrounding community. Results could be compared with those 
from this study to look at ways to improve both communities' processes of integration with each other.

A fourth recommendation is that other case studies similar to this one be carried out in the Northwest and in other regions of the United States, which could then be compared with this study. A fifth recommendation is that a large scale review of many such studies be carried out to give them external validity and to make general statements about recent immigrant Latino communities in the United States.

\section{POSTSCRIPT}

Recommendations for more bilingual services have the objectives of improving two-way integration and equal access to resources for both the Latino and surrounding communities. However, recent trends in the United States, namely the English-only movement and anti-immigration activity, as discussed in chapter II, may hinder these efforts. After this research was completed, and thesis defended, a ruling was publicized that indicated that enacting service delivery as the researcher recommends may become more difficult.

In June of 1994, the Supreme Court ruled not to review a California Ninth Court of Appeals decision in favor of an employer in San Francisco denying a bilingual Spanish-English employee the right to speak Spanish in the workplace. The Supreme Court held that the court of Appeals ruling did not 
violate federal anti-discrimination law. The Supreme court's ruling is different than past rulings, and important because it may have set legal precedent for further court rulings against the use of non-English languages. The ruling seems to be a part of the English-only movement and the antiimmigration mood in the country, and may likely be a green light to pass more English-only rules. It may encourage an antagonistic work environment and create a more hostile workplace.

In a radio piece reported by Latino USA (1994), the argument was presented that this supreme court ruling is not about the right to speak Spanish, Chinese, or any other nonEnglish language. This is about the right to be free from discrimination based on national origin. The ruling did not find there to be disparate impact on a class of people defined by their language. Yet, to many people this precisely what has occurred. According to this Latino USA report, the action of the Ninth Circuit court has austensibly cut off access to freedom from discrimination based on national origin as defined by the Civil Rights Act of 1964. The researcher finds this argument compelling. 
REFERENCES

Baker, K., \& dekanter, A. (1981). Effectiveness of bilingual education: A review of the literature.

Washington, DC: United States Department of Education, office of Planning, Budget, and Evaluation.

Berlin, J.A. (1988). Rhetoric and ideology in the writing class. College English, 50, 477-494.

Birman, B. F., \& Ginsburg, A. L. (1981). Addressing the needs of language-minority children: Issues for federal policy. Washington, DC: United States Department of Education, Office of Planning, Budget, and Evaluation.

Christian, C. (1982). Reading in Spanish as a mode of language maintenance in the United States. In J.A. Fishman \& G. D. Keller (Eds.), Bilingual education for Hispanic students in the United States (pp. 356-367). New York: Teachers College Press.

Cross Cultural Resource Center. (1981). The federal policy toward lanquage education: Pendulum or progress? Sacramento, CA: California State University, Department of Anthropology.

Curiel, H., Rosenthal, J. A., \& Richek, H. G. (1986). Impacts of bilingual education on secondary school grades, attendance, retentions and drop-outs. Hispanic Journal of Behavioral Sciences, 8, 357-367.

Daniels, H. A. (1990). The roots of language protectionism. In H. A. Daniels (Ed.), Not only English: Affirming America's multilingual heritage (pp. 3-12). Urbana, IL: National Council of Teachers of English.

De Leon, D. (1908a, June 9). Applause and groans [editorial]. Daily People, Reprinted in Staff. (1992, May 16). Daniel De Leon: On racism and immigration. The people, pp. 1S-2S. 
De Leon, D. (1908b, August 4). Shaming a socialist

[editorial]. Daily People. Reprinted in staff. (1992, May 16). Daniel De Leon: On racism and immigration.

The People, p. 2S.

De Leon, D. (1909, October 26). A tiger, not to be awakened [editorial]. Daily People. Reprinted in staff. (1992, May 16). Daniel De Leon: On racism and immigration. The People, p. 3S.

Dillin, J. (1992, April 15). Buchanan looks toward 1996. The Christian science Monitor, p. 8 .

Dueñas-Gonzalez, R. (1990). In the aftermath of the ELA: stripping language minorities of their rights. In $\mathrm{H}$. A. Daniels (Ed.), Not only English: Affirming America's multilingual heritage (pp. 49-60). Urbana, IL:

National Council of Teachers of English.

Durand, J., \& Massey, D. S. (1992). Mexican migration to the United States: A critical review. Latin American Research Review, 27 (2), 3-42.

Freire, P. (1973) pedagogy of the oporessed. (M. Bergman Ramos, Trans.) New York: The Searbury Press.

Hayes, E. (1989). Hispanic adults and ESL programs: Barriers to participation. TESOL Quarterly, 23, 47-63.

Hobbs, D. (1987). Stragegy of Needs Assessment. In Johnson, D. E.,Meiller, L. R., Miller, L. C., \& Summers, G. F. (Eds.), Needs assessment: Theory and methods (pp. 2034). Ames, IA: Iowa State University Press.

Ilich, I. (1970). Deschooling society. New York: Harper \& Row.

Ishiyama, F. I., \& Westwood, M. J. (1992). Enhancing client-validating communication: Helping discouraged clients in cross-cultural adjustment. Journal of Multicultural Counseling and Development, 20, 50-63.

Johnson, D. M. (1992). Approaches to research in a second language learning. White Plains, NY: Longman Publishing Group.

Judd, E. L. (1990). The federal English language amendment. In H. A. Daniels (Ed.), Not only English: Affirming America's multilingual heritage (pp. 37-46). Urbana, IL: National Council of Teachers of English. 
Kaplan, M. S., \& Marks, G. (1990). Adverse effects of acculturation: Psychological distress among Mexican American young adults. Social Science Medicine, 31 , 1313-1319.

Kellerman, B. (1987). Forward. In Johnson, D. E., Meiller, L. R.,Miller, L. C., \& Summers, G. F. (Eds.), Needs assessment: Theory and methods (pp. vii-ix). Ames, IA: Iowa State University Press.

Latino USA [radio show]. (1994, June 25). Washington, DC: National Public Radio.

The Latinoization of American culture [Sidebar]. (1992). CO Researcher, $\underline{2}, 942$.

Latinos on the Rise. (1993). The Futurist, 27 (1), 48-49.

Liebkind, K. (1989). The identity of a a minority. Journal of Multilinqual and Multicultural Development, 10, 4757 .

Mann, D. (1984, September). Achieving zero net migration. USA Today, pp. 10-12.

Manoleas, P., \& Carillo, E. (1991). A culturally syntonic approach to the field education of Latino students. Journal of Social Work Education, 27, 135-144.

McKillip, J. (1987). Needs analysis: Tools for the human services and education. Newbury Park, CA: Sage Publications, Inc.

Molesky, J. (1988). Understanding the American linguistic mosaic: A historical overview of language maintenance and language shift. In S. McKay \& S. C. Wong (Eds.), Language diversity: Problem or resource? (pp. 29-68). New York: Newbury House.

Moyerman, D. R. , \& Forman, B. D. (1992). Acculturation and adjustment: A meta-analytic study. Hispanic Journal of Behavioral Sciences, 14, 163-200.

Passel, J. S. (1992). Demographic profile [Sidebar]. Report on the Americas, $26(2), 21$.

Raimes, A. (1991). Out of the woods: Emerging traditions in the teaching of writing. TESOL Ouarterly, 25, 407430 . 
Rimer, S. (1991, November 28). For immigrants, English helps them feel at home. The New York Times, p. Al.

Rodriguez, R. (1988, July 11). The fear of losing a culture. Time, p. 84 .

Rothman, J., \& Grant, L. M. (1987). Approaches and Models of Community Intervention. In D. E. Johnson, L. R. Meiller, L. C. Miller, \& G. F. Summers (Eds.), Needs assessment: Theory and methods (pp. 35-44). Ames, IA: Iowa State University Press.

Ruiz, R. (1987, April). Foreign language study and bilingual education. Paper presented at the annual meeting of the American Educational Research Association, Washington, DC.

Salholz, E., Gonzalez, D. L., Hurt III, H., \& Wingert, P. (1989, February 20). Say it in English. Newsweek, pp. $22-23$.

Santiago, I. S. (1982). Third world vernacular/bimultilingual curricula issues. In B. Hartford, A. Valdman, \& C. R. Foster (Eds.), Issues in international bilingual education: The role of the vernacular (pp. 113-139). New York: Plenum Press.

Shorris, E. (1992a, October 28). Latino, sí. Hispanic, no. The New York Times, p. A21.

Shorris, E. (1992b). Latinos: The complexity of identity. Report on the Americas, 26 (2), 19-26.

Skutnabb-Kangas, T. (1990). Legitimating or delegitimating new forms of racism--the role of researchers. Journal of Multilingual and Multicultural Development, 11, 77100 .

Stein, R. F. (1990). Closing the 'achievement gap' of Mexican Americans: A question of language, learning style, or economics? Journal of Multilingual and Multicultural Development, 11, 405-419.

Tollefson, J. (1991). Planning language, planning inequality. London: Longman.

Trasvina, J. (1988). Official English/English only: More than meets the eye. Washington, DC: The National Education Association. 
Trueba, H.. T. (1979). Research, journalism or politics. In C. Barnett-Mizrahi \& H. T. Trueba (Eds.), Bilingual multicultural education: Theory to practice (pp. 430440). Rowley, MA: Newberry House Publishers.

Valencia, A. A. (1992). Multicultural education:

Contemporary perspectives and orientations for teachers and counselors. Journal of Multicultural counseling and Development, 20, 132-142.

Who are America's Hispanics [Graphic]. (1992). CO Researcher, 2. 938 .

Young, R. (1991). Intercultural communication and criticism [review article]. Journal of Multilingual and Multicultural Development, 12, 301-308.

Zenger, W. F., \& Zenger, S. K. (1982). Curriculum planning: A ten-step process. Palo Alto, CA: Fort Hays state University, $R$ \& $E$ Research Associates, Inc. 
APPENDIX A

QUESTIONNAIRE:

SPANISH AND ENGLISH 
CUESTIONARIO

General

1) Mi primer idioma es:

2) En general, mi habilidad para comunicarme en inglés es: $\square$ Excelente $\square$ Muy Buena $\square$ Regular $\square$ No Tan Buena $\square$ Pobre

3) En general, mi habilidad para leer y escribir en inglés es:

$\square$ Excelente $\square$ Muy Buena $\square$ Regular $\square$ No Tan Buena $\square$ pobre

4) En general, mi habilidad para comunicarme en español es:

$\square$ Excelente $\square$ Muy Buena $\square$ Regular $\square$ No Tan Buena $\square$ pobre

5) En general, mi habilidad para leer y escribir en español es:

$\square$ Excelente $\square$ Muy Buena $\square$ Regular $\square$ No Tan Buena $\square$ Pobre

6) En general, me siento con libertad de utilizar español para communicarme en ésta ciudad:

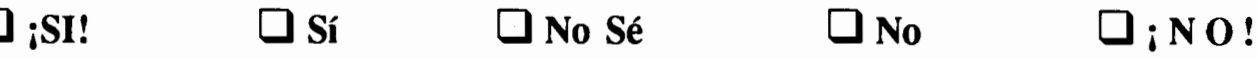

7) En general, me siento con libertad de utilizar español escrito en ésta ciudad:

$\square_{\text {iSI! }} \square$ Sí $\square$ No Sé $\square$ No $\square_{i}$ N O !

8) En general, la habilidad de la gente en ésta ciudad para comunicarse conmigo en español es:
Excelente
Muy Buena
Regular
No Tan Buena $\square$ Pobre

9) En general, hay materiales útiles disponibles en español en ésta ciudad:
¿ iSI!
Sí
$\square$ No Sé
$\square_{\mathbf{i}} \mathbf{N O} \mathbf{O}$

Empleo

10) Es difícil encontrar y conservar un empleo en ésta ciudad:
$\square_{\text {¡SI! }}$
$\square$ Sí
No Sé
$\square_{\text {i N O ! }}$

Si contesta SI, porque:

11a) 1. Es difícil comunicarse en inglés:
$\square$ hablar por teléfono
negociar
$\square$ hacer preguntas
$\square$ comprender $\square$ dar/recibir ins
$\square$ cursos de capacitación están en inglés
$\square$ requisito de trabajo

$\square$ otros

12a) 2. Es difícil leer y escribir en inglés:
anuncios
clasificados
$\square$ solicitudes de empleo
listas de empleo
$\square$ requisito de trabajo
materiales de capacitación están en inglés
Dotros 
13a) 3. Otras cosas

Si contesta NO, porque:

11b) 1. Puedo comunicarme en inglés:
Dablar por teléfono
negociar
comprender
hacer preguntas
$\square$ requisito de trabajo
$\square$ cursos de capacitación están en inglés Dotros

12b) 2. Puedo leer y escribir en inglés:
$\square$ anuncios clasificados
listas de empleo
$\square$ solicitudes de empleo
$\square$ materiales de capacitación
$\square$ requisito de trabajo

Dotros

13b) 3. Otras cosas

14) En general, los jefes valoran mi español:
$\square_{\text {;SI! }}$
$\square$ Sí
$\square$ No Sé
No
; NO!

15a) Si contesta SI, lo valoran por:
$\square$ mi habilidad para comunicarme en español
mi habilidad para leer $y$ escribir en español
Dotros

15b) Si contesta NO, no lo valoran por:

mi habilidad para comunicarme en español

$\square$ mi habilidad para leer y escribir en español Dotros

Habitación

16) Es difícil encontrar casa en ésta ciudad:

$\square_{i S I !} \square$ Sí $\square$ No Sé $\quad \square_{\text {No }}$.

Si contesta SI, porque:

17a) 1. Es difícil comunicarse en inglés:
hacer preguntas comprender
negociar con el casero/gerente $\square$ hablar por teléfono
Dotros

18a) 2. Es difícil leer y escribir en inglés:
anuncios clasificados
$\square$ solicitudes de renta $\square$ anun

19a) 3. Otras cosas 
Si contesta NO, porque:

17b) 1. Puedo comunicarme en inglés:

\begin{tabular}{ll}
$\square$ hacer preguntas \\
\hline comprender & habociar con el casero/gerente \\
$\square$ otros
\end{tabular}

18b) 2. Puedo leer y escribir en inglés:

$\square$ anuncios clasificados $\square$ solicitudes de renta
anuncios de casas de renta en tableros

19b) 3. Otras cosas

20) Mi español me ayuda a encontrar casa en ésta ciudad:
$\square_{\text {iSI! }}$ $\square$ Sí $\square$ No Sé $\square$ No ; NO :

21a) Si contesta SI, porque:
$\square$ puedo comunicarme en español $\square$ puedo leer y escribir en español 口otros

21b) Si contesta NO, porque:

mi habilidad para comunicarme en español no es necesaria $\square$ mi habilidad para leer y escribir español no es necesaria Dotros

Compañias de Luz/Teléfono y Agencias de Servicio Social

22) Tengo (o tuve) problemas con las compañías de luz/teléfono en ésta ciudad: DSI $\quad \mathrm{NNO}$

23a) Si contesta SI, estos problemas son:

24a) No habría tenido estos problemas si las compañías usaran español además del inglés:
$\square_{\text {;SI! }}$
Sí
$\square$ No Sé
$\square$ No
$\square_{i} \mathbf{N O}$ !

23b) Si contesta $\mathbf{N O}$, mi habilidad para el inglés me ha ayudado para no tener problemas:
$\square_{i S I !}$
$\square$ Sí
No Sé
No
$\square_{i} \mathbf{N O}$ !

25) Es difícil tener acceso a servicios proporcionados por agencias de servicio social en ésta ciudad:
$\square_{i S I !}$
Sí
No Sé
No
$\square_{\text {; N O ! }}$

26a) Si contesta SI, estas dificultades son: 
27a) No habría tenido estas dificultades si las agencias de servicio social usaran español además del inglés:

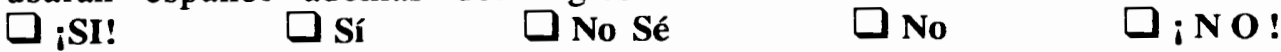

26b) Si contesta NO, mi habilidad para el inglés me ha ayudado para no tener dificultades:
$\square_{\text {iSI! }}$
$\square$ Sí
$\square$ No Sé
$\square$ No
; N O !

Atención Médica

28) Yo recibo o mis hijos reciben atención médica en ésta ciudad:

$\square$ S I

$\square \mathrm{NO}$

29a) Si contesta NO, porque:

$\square$ los doctores hablan inglés

$\square$ no sé donde ir ya que la información está en inglés

口otros

29b) Si contesta SI, la atención médica está en:
Español
Español y Inglés
Inglés

30) Puedo comunicarme con el doctor:
$\square$ Siempre $\square \mathbf{L a}$
mayor
parte
$\square$ A I gunas
Veces, las cosas
importantes
Un Poco, pero no las cosas
importantes

31a) Si contesta Algunas Veces, Un Poco, o Nunca, yo:
$\square$ escucho
adivino lo que dicen
encuentro alguien que interprete

Dotros

32) Las instrucciones escritas de las recetas médicas o de control de la natalidad están en:

Español

Español y Inglés

Inglés

33) Entiendo estas instrucciones:

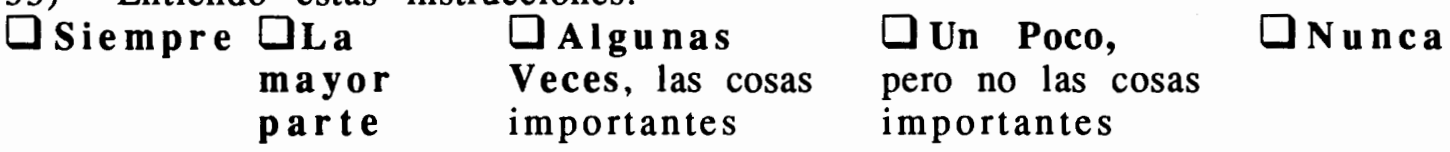

34) Cuando las instrucciones están en inglés, yo:

$\square$ sigo las instrucciones
$\square$ confío en la memoria o adivino
$\square$ encuentro alguien que traduzca

Dotro 
Cuidado de Niños

35) Mis hijos son:

bebés

$\square$ de edad pre-escolar

de kinder o escolar

36) Es difícil encontrar donde cuiden niños o escuela para mis hijos:
$\square$;SI!
$\square$ Sí
$\square$ No Sé
No
$\square_{i} \mathbf{N O}$ !

Si contesta SI, porque:

37a) 1. Es difícil comunicarse con maestros en inglés:

$\square$ hablar por teléfono $\square$ hacer preguntas

$\square$ comprender $\square$ dar/recibir información

Dotros

38a) 2. Es difícil leer y escribir en inglés:

$\square$ información sobre escuelas o guarderías

solicitudes de escuelas o guarderías

$\square$ materiales escolares o de guarderías

Dotros

39a) 3. Otras cosas

Si contesta NO, porque:

37b) 1. Puedo comunicarme en inglés:

$\square$ hablar por teléfono $\square$ hacer preguntas

$\square$ comprender $\square$ dar/recibir información

Dotros

38b) 2. Puedo leer y escribir en inglés:

$\square$ información sobre escuelas o guarderías
$\square$ solicitudes de escuelas o guarderías
$\square$ materiales escolares o de guarderías

Dotros

39b) 3. Otras cosas

40) Consigo cuidado de niños a través de:

$\square$ el distrito escolar $\square$ amigos $\square$ guarderías $\square$ familia

41) Me comunico con la persona que cuida mis hijos o sus maestros en:

$\square$ Español $\square$ Español y Inglés $\square$ Inglés

42) Mi habilidad para comunicarme con la persona que cuida a mis hijos o sus maestros es:

$\square$ Excelente $\square$ Muy Buena $\square$ Regular $\square$ No Tan Buena $\square$ Pobre

43) La habilidad de la persona que cuida a mis hijos o sus maestros para comunicarse conmigo es:

$\square$ Excelente $\square$ Muy Buena $\square$ Regular $\square$ No Tan Buena $\square$ Pobre 
44) Mi guardería o escuela ideal es aquella en donde los maestros usan:

Español

$\square$ Español y Inglés

$\square$ Inglés

Crisis (opcional)

45) Hubo (o hay) violencia doméstica en mi casa dirigida hacia mi o mis hijos:

46) Busqué ayuda: $\square$ SI I

$\square$ NO

$\square$ NO

47a) Si la respuesta es SI, busqué ayuda:

$\square$ con una amiga/un amigo

con una agencia

Dotros

48a) Busqué ayuda allí porque:

$\square$ siento confianza allí

$\square$ se habla español allí

escuché que era un buen lugar para ir

Dotros

47b) Si contesta NO, la falta de inglés fué un obstáculo para buscar ayuda:

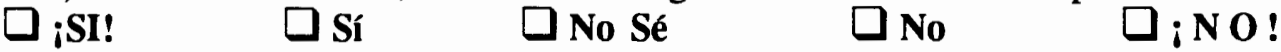

48b) Habría buscado ayuda si hubiera sabido de una agencia donde se habla español:

$\square_{\text {;SI! }}$

$\square$ Sí

$\square$ No Sé

$\square$ No

$\square_{i}$ NO! 
QUESTIONNAIRE

General

1) My first language is:

2) In general, my ability to communicate in English is:

$\square$ Excellent $\square$ Very Good $\square$ OK $\square$ Not So Good $\square$ Poor

3) In general, my ability to read and write in English is:

$\square$ Excellent $\square$ Very Good $\square$ OK $\square$ Not So Good $\square$ Poor

4) In general, my ability to communicate in Spanish is:

$\square$ Excellent $\square$ Very Good $\square$ OK $\square$ Not So Good $\square$ Poor

5) In general, my ability to read and write in Spanish is:

$\square$ Excellent $\square$ Very Good $\square$ OK $\square$ Not So Good $\square$ Poor

6) In general, I feel free to use Spanish to communicate in this city:

$\square$ YES! $\square$ Yes $\square$ Don't Know $\square$ No $\square$ N O !

7) In general, I feel free to use written Spanish in this city:

$\square$ YES! $\square$ Yes $\square$ Don't Know $\square$ No $\square$ N O

8) In general, the ability of people in this city to communicate with me in Spanish is:

$\square$ Excellent $\square$ Very Good $\square$ oK $\square$ Not So Good $\square$ Poor

9) In general, there are useful materials available in Spanish in this city:

$\square$ YES! $\square$ Yes $\square$ Don't Know $\square$ No $\square$ N O !

Employment

10) It is difficult to find or maintain a job in this city:

$\square$ YES! $\square$ Yes $\square$ Don't Know $\square$ No $\square$ N O !

If YES, this is because:

11a) 1. It is difficult to communicate in English:

$\square$ talk on phone $\square$ ask questions

$\square$ negotiate $\square$ job requirement

$\square$ understand $\square$ give/receive directions

$\square$ skill building courses are in English

$\square$ other

12a) 2. It is difficult to read and write in English:

$\square$ classified ads $\square$ employment applications

$\square$ job listings $\square$ job requirement

$\square$ skill building course materials are in English

aother 
13a) 3. Other things

If NO, this is because:

11b) 1. I can conmunicate in English:
$\checkmark$ talk on phone
$\square$ negotiate
ask questions
$\square$ job requirement
understand
$\square$ give/receive directions
$\square$ skill building courses are in English
Dother

12b) 2. I can read and write in English:
$\square$ classified ads
$\square$ employment applications
job listings
$\square$ job requirement
skill building course materials are in English Dother

13b) 3. Other things

14) In general, employers value my Spanish:

$\square$ YES! $\square$ Yes $\square$ Don't Know $\square$ No $\square$ N O !

15a) If YES, they value:

$\square$ my ability to communicate in Spanish

$\square$ my ability to read and write in Spanish

Dother

15b) If N O, they don't value:

my ability to communicate in Spanish

my ability to read and write in Spanish

Dother

Housing

16) It is difficult to find housing in this city:

$\square$ YeS! $\square$ Yes $\square$ Don't know $\square$ No $\square$ No!

If YES, this is because:

17a) 1. It is difficult to communicate in English:

$\square$ ask questions $\square$ negotiate with landlord/manager

$\square$ understand $\square$ talk on phone

Dother

18a) 2. It is difficult to read and write in English:
$\square$ classified ads
housing board
Dother

19a) 3. Other things 
If $\mathbf{N O}$, it is not difficult because:

17b) 1. I can communicate in English:

\begin{tabular}{l} 
ask questions \\
$\begin{array}{l}\text { negotiate with landlord/manager } \\
\text { understand }\end{array}$ \\
\hline other on phone
\end{tabular}

18b) 2. I can read and write in English:
classified ads
housing board
Dother

19b) 3. Other things

20) My Spanish helps me find housing in this city:

$\square$ YES! $\square$ Yes $\square$ Don't Know $\square$ No $\square$ NO!

21a) If YES, this is because:

I can communicate in Spanish

$\square$ I can read and write in Spanish

Dother

21b) If NO, this is because:

$\square$ my ability to communicate in Spanish is not needed

my ability to read and write in Spanish is not needed

Dother

Utility/Telephone Companies and Social Service Agencies

22) I have (or had) problems with utility or telephone companies in this city: DYES

DNO

23a) If YES, these problems are:

24a) I would not have had these problems if the utility/telephone companies used Spanish in addition to English:

$\square$ YES! $\square$ Yes $\square$ Don't Know $\square$ No $\square$ NO!

23b) If NO, my English skills have helped me avoid problems:
DYES
Yes
Don't Know
No
口 O :

25) It is difficult to access services provided by social service agencies in this city:

$\square$ YES! $\square$ Yes $\square$ Don't Know $\square$ No $\square$ No!

26a) If YES, these difficulties are:

27a) I would not have had these difficulties if the social service agencies used Spanish in addition to English:

$\square$ YES! $\square$ Yes $\square$ Don't know $\square$ No $\square$ No ! 
26b) If NO, my English skills have helped me avoid difficulties:

$\square$ YES! $\square$ Yes $\square$ Don't Know $\square$ No $\square_{\text {NO }}$ !

Medical Care

28) I or my children get medical care in this city:

$\square$ YES

口NO

29a) If NO, this is because:

$\square$ the doctors speak English

I don't know where to go as medical information is in English Dother

29b) If YES, the medical care is in:
$\square$ Spanish
Spanish and English
English

30) I can communicate with the doctor:
Always Mostly, the important things
Sometimes, not all the important things
$\square$ A little, $\square$ Never but not the important things

\section{$\square$ listen and do my best to understand \\ guess the meaning \\ find someone to interpret}

31a) If my answer is Sometimes, A little, or Never, I:

Dother

32) The written directions for medical or birth control prescriptions are in: $\square$ Spanish $\square$ Spanish and English $\square$ English

33) I understand these directions:

$\square$ Always
$\begin{aligned} & \square \text { Mostly, } \\ & \text { the important } \\ & \text { things }\end{aligned}$ $\begin{aligned} & \text { not all the } \\ & \text { important things important things }\end{aligned}$

34) When the prescriptions are in English, I:

$\square$ follow the directions

$\square$ rely on memory or guess

$\square$ find someone to translate

Dother

\section{Child Care}

35) My children are: $\square$ infants $\square$ preschool-age $\square$ kindergarten or school-age

36) It is difficult to get child care or schooling for my children:
QYES!
$\square$ Yes
$\square$ Don't Know
$\square$ No
J O ! 
If YES, this is because:

37a) 1. It is difficult to communicate with teachers in English:
$\square$ talk on the understand phone
$\square$ ask questions
$\square$ give/receive information Dother

38a) 2. It is difficult to read and write in English:

$\square$ information about school or child care centers

$\checkmark$ school or child care applications

school or child care materials

Dother

39a) 3. Other things

If NO, this is because:

37b) 1. I can communicate in English:

$\square$ talk on the phone ask questions
understand
$\square_{\text {gother }}$

38b) 2. I can read and write in English:

\begin{tabular}{l} 
information about school or child care centers \\
school or child care applications \\
school or child care materials \\
\hline other
\end{tabular}

39b) 3. Other things

40) I get child care through:

$\square$ school district $\square$ friend $\square$ child care center $\square$ family
Dother

41) I communicate with my child care provider or my children's teachers in: Spanish $\square$ Spanish and English

42) My ability to communicate with my child care provider or children's teachers is:

$\square$ Excellent $\square$ Very Good $\square$ oK $\square$ Not So Good $\square$ Poor

43) The ability of my child care provider or children's teachers to communicate with me in Spanish is:

$\square$ Excellent $\square$ Very Good $\square$ OK $\square$ Not So Good $\square$ Poor

44) My ideal child care center or school is where teachers use: Spanish

Spanish and English

English 
CRISIS (optional)

45) There was (or is) domestic violence in my house directed toward me or my children:

$\begin{array}{lll} & \square Y E S & \square_{N O} \\ \text { 46) I looked for help: } & \square \text { YES } & \square_{N O}\end{array}$

47a) If YES, I looked for help:

$\square$ with a friend

$\square$ with an agency

Dother

48a) I sought help there because:

$\square$ I feel trust there

Spanish is spoken there

$\square$ I heard it is a good place to go

Dother

47b) If NO, lack of English got in the way of my seeking help:

$\square$ YES! $\square$ Yes $\square$ Don't Know $\square$ No $\square$ N O !

48b) I would have sought help if I had known of an agency where Spanish is spoken:

ØYES!

$\square$ Yes

$\square$ Don't Know

$\square$ No

$\square \mathbf{N O}$ ! 
APPENDIX B

COMPILATION OF

PARTICIPANTS' RESPONSES

TO QUESTIONNAIRE 
General Language

My first language is: (30 responses)

Spanish: 29

Indigenous: 1

In general, my ability to communicate in English is: (30 responses)

Not So Good/Poor: 23

OK: 6

Excellent/Very Good: 1

In general, my ability to read and write in English is: (32 responses)

Not So Good/Poor: 23

OK: 8

Excellent/Very Good: 1

In general, my ability to communicate in Spanish is: (30 responses)

Excellent/Very Good: 26

OK: 4

Not So Good/Poor: 0

In general, my ability to read and write in Spanish is: (30 responses)

Excellent/Very Good: 24

OK: 4

Not So Good/Poor: 2

In general, I feel free to use Spanish to communicate in this city:

responses )

YES: 21

NO: 13

Don't Know: 0

In general, I feel free to use written Spanish in this city: (31 responses) YES: 18

NO: 13

Don't Know: 0

In general, the ability of people in this city to communicate with me in

Spanish is: (31 responses)

Excellent/Very Good: 15

Not So Good/Poor: $9+$

OK: 7+

In general, there are useful written materials available in Spanish in this city:

(30 responses)

NO: $13+$

YES: 13

Don't Know: 4 
Employment

It's difficult to find and maintain a job in this city: (31 responses)

YES: 23

NO: 6

Don't Know: 2

If YES, this is because:

1. It's difficult to communicate in English:

Ask questions: 17

Give/receive instructions: 16

Job requirement: 15

Talk on the phone: 15

Understand: 15

Skill building courses are in English: 13

Negotiate: 9

Other: 2

2. It's difficult to read and write in English:

Employment applications: 18

Job requirement: 18

Skill building course materials are in English: 16

Job listings: 14

Classified ads: 13

Other: 0

3. Other things: 11

If NO, it is not difficult because:

1. I can communicate in English:

Ask questions: 4

Understand: 4

Talk on the phone: 3

Give/receive instructions: 2

Job requirement: 2

Negotiate: 2

Skill building courses are in English: 2

Other: 0

2. I can read and write in English:

Classified ads: 2

Employment applications: 2

Job listings: 2

Skill building course materials are in English: 2

Job requirement: 1

Other: 0

3. Other things: 5

In general, employers value my Spanish: (33 responses)

NO: 18

YES: 11

Don't Know: 4 
If YES, they value:

My ability to communicate in Spanish: 8

Other: 7

My ability to read and write in Spanish: 2

If NO, they don't value:

My ability to communicate in Spanish: 13

My ability to read and write in Spanish: 13

Other: 13

\section{Housing}

It's difficult to find housing in this city: (30 responses) YES: 23

NO: 4

Don't Know: 3

If YES, this is because:

1. It's difficult to communicate in English:

Ask questions: 17

Negotiate with the landlord/manager: 16

Understand: 16

Talk on the phone: 14

Other: 4

2. It's difficult to read and write in English:

Housing applications: 19

Classified ads: 10

Housing board: 10

Other: 2

3. Other things: 16

If NO, it is not difficult because:

1. I can communicate in English:

Ask questions: 2

Negotiate with the landlord/manager: 2

Understand: 2

Talk on the phone: 1

Other: 0

2. I can read and write in English:

Classified ads: 2

Housing board: 2

Housing applications: 1

Other: 0

3. Other things: 3 (9I, 10J, 18P)

My Spanish helps me find housing in this city: (30 responses)

NO: 21

Don't Know: 5

YES: 4 
If YES, this is because:

I can communicate in Spanish: 4

I can read and write in Spanish: 3

Other: 3

If NO, this is because:

My ability to communicate in Spanish isn't needed: $\mathbf{2} 1$

My ability to read and write in Spanish isn't needed: 17

Other: 13

\section{Utility/Phone Companies and Social Service Agencies}

I have (or had) problems with utility or telephone companies in this city: responses)

NO: 21

YES: 9

If YES, these problems are: 7

I wouldn't have these problems if the utility/telephone companies used Spanish in addition to English: (9 reponses)

YES: 6

Don't Know: 3

NO: 0

If NO, my English skills have helped me avoid problems: (21 responses)

NO: 13

YES: 4

Don't Know: 4

It's difficult to access services provided by social service agencies in this city: (30 responses)

NO: 15

YES: 14

Don't Know: 1

If YES, these difficulties are: 12

I wouldn't have these problems if the social service agencies used Spanish in addition to English: (14 responses)

YES: 12

Don't Know: 1

NO: 1

If NO, my English skills have helped me avoid difficulties: (15 responses)

N0: 11

YES: 3

Don't Know: 1 
Medical Care

I or my children get medical care in this city: (30 responses)

YES: 29

NO: 1

If NO, this is because: (1 response)

Other: 1

The doctors speak English: 0

I don't know where to go as medical information is in English: 0

If YES, the medical care is in: (33 responses)

Spanish and English: 16

English: 13+

Spanish: 4

I can communicate with the doctor: (30 responses)

Always/Mostly: 10

Sometimes, the important things: 10

A Little, but not the imortant things/Never: 10

If my answer is Sometimes, A Little, or Never, I:

Find someone to interpret: 14

Listen and do my best to understand: 14

Guess the meaning: 12

Other: 4

The written directions for medical prescriptions or birth control are in: responses)

English: $18+$

Spanish and English: 9

Spanish: 6

I understand these directions: (32 responses)

Sometimes, the important things: 14

Always/Mostly: 11

A Little, but not the imortant things/Never: 7

When the directions are in English, I:

Find someone to translate: $\mathbf{2 5}$

Follow the directions: 13

Rely on memory or guess: 5

Other: 5

\section{Child Care}

My children are:

Babies: 19

Preschool age: 15

Kindergarten or school age: 14 
It's difficult to get child care or schooling for my children: (31 responses) NO: 17

YES: 10

Don't Know: 4

If YES, this is because:

1. It's difficult to communicate with teachers in English:

Give/receive information: 7

Understand: 7

Talk on the phone: 6

Ask questions: 5

Other: 3

2. It is difficult to read and write in English:

Information about school or child care centers: 6

School or child care materials: 5

School or child care applications: 4

Other: 1

3. Other things: 6

If NO, it is not difficult because:

1. I can communicate in English:

Ask questions: 3

Give/receive information: 2

Talk on the phone: 2

Understand: 2

Other: 0

2. I can read and write in English:

Information about school or child care centers: 4

School or child care applications: 3

School or child care materials: 3

Other: 0

3. Other things: $\mathbf{1 3}$

I get child care through:

Friends: 18

Family: 16

Head Start: 13

The school district: 12

Child care centers: 1

I communicate with my child care provider or my children's teachers in:

responses)

Spanish: 20

English: 11+ (including 1+ "I can't")

Spanish and English: 11

My ability to communicate with my child care provider or my children's teachers is: (34 responses)

Excellent/Very Good: 24

OK: 5

Not So Good/Poor: 5 
The ability of my child care provider or my children's teachers to communicate with me is: (34 responses)

Excellent/Very Good: 25

Not So Good/Poor: 5

OK: 4

My ideal child care center or school is where teachers use: (30 responses) Spanish and English: 23

Spanish: 4

English: 3

\section{Crisis (Optional)}

There was (or is) domestic violence in my house directed toward me or my children: (30 responses)

NO: 23

YES: 7

If YES, I looked for help:

YES: 7

NO: 0

If YES, I looked for help:

With a friend: 6

With an agency: 5

Other: 1

I looked for help there because:

I feel trust there: 6

I heard it was a good place to go: 6

Spanish is spoken there: 5

Other: 3

If NO, lack of English got in the way of my looking for help: (0 responses) YES: 0

Don't Know: 0

NO: 0

I would have looked for help if I had known of an agency where Spanish is spoken: (1 response)

YES: 1

Don't Know: 0

NO: 0 